Please do not remove this page

RMIT

UNIVERSITY

\title{
A mechanistic interpretation of the comparative in-plane mechanical properties of 3D woven, stitched and pinned composites
}

Mouritz, Adrian; Cox, Brian

https://researchrepository.rmit.edu.au/esploro/outputs/9921857911001341/filesAndLinks?institution=61RMIT_INST\&index=null

Mouritz, A., \& Cox, B. (2010). A mechanistic interpretation of the comparative in-plane mechanical properties of 3D woven, stitched and pinned composites. Composites Part A-Applied Science And Manufacturing, 41(6), 709-728. https://doi.org/10.1016/j.compositesa.2010.02.001

Document Version: Accepted Manuscript

Published Version: https://doi.org/10.1016/j.compositesa.2010.02.001

Repository homepage: https://researchrepository.rmit.edu.au

(c) 2010 Elsevier Ltd. All rights reserved

Downloaded On 2023/04/27 01:12:51 +1000 
Thank you for downloading this document from the RMIT Research Repository.

The RMIT Research Repository is an open access database showcasing the research outputs of RMIT University researchers.

RMIT Research Repository: http://researchbank.rmit.edu.au/

\section{Citation:}

Mouritz, A and Cox, B 2010, 'A mechanistic interpretation of the comparative in-plane mechanical properties of 3D woven, stitched and pinned composites', Composites Part A-Applied Science And Manufacturing, vol. 41, no. 6, pp. 709-728.

See this record in the RMIT Research Repository at:

http://researchbank.rmit.edu.au/view/rmit:5528

Version: Accepted Manuscript

Copyright Statement: (c) ( 2010 Elsevier Ltd. All rights reserved

Link to Published Version:

http://dx.doi.org/10.1016/j.compositesa.2010.02.001 


\title{
A MECHANISTIC INTERPRETATION OF THE COMPARATIVE IN-PLANE MECHANICAL PROPERTIES OF 3D WOVEN, STITCHED AND PINNED COMPOSITES
}

\author{
A.P. Mouritz* \\ School of Aerospace, Mechanical and Manufacturing Engineering \\ Royal Melbourne Institute of Technology \\ GPO Box 2476V, Melbourne, Victoria, Australia 3001 \\ B.N. Cox \\ Teledyne Scientific Co LLC \\ 1049 Camino Dos Rios, Thousand Oaks, CA 91360, USA
}

Composites A

\footnotetext{
* Corresponding author

Tel: +61399258069

Fax: +61 399258099

e-mail: adrian.mouritz@rmit.edu.au
} 


\begin{abstract}
A comparison of substantial published data for 3D woven, stitched and pinned composites quantifies the advantages and disadvantages of these different types of through-thickness reinforcement for in-plane mechanical properties. Stitching or 3D weaving can either improve or degrade the tension, compression, flexure and interlaminar shear properties, usually by less than $20 \%$. Furthermore, the property changes are not strongly influenced by the volume content or diameter of the throughthickness reinforcement for these two processes. One implication of this result is that high levels of through-thickness reinforcement can be incorporated where needed to achieve high impact damage resistance. In contrast, pinning always degrades in-plane properties and fatigue performance, to a degree that increases monotonically with the volume content and diameter of the pins. Property trends are interpreted where possible in terms of known failure mechanisms and expectations from modelling. Some major gaps in data and mechanistic understanding are identified, with specific suggestions for new standards for recording data and new types of experiments.
\end{abstract}

Keywords: Polymer matrix composites, 3D weaving, stitching, pins, throughthickness reinforcement, mechanical properties, failure mechanisms. 


\section{INTRODUCTION}

Composites containing high densities of in-plane fibers along with lesser densities of fibers oriented through the thickness can offer an attractive combination of high inplane mechanical properties and enhanced delamination toughness and impact damage resistance [1-11]. The through-thickness fibres can be inserted using a variety of textile processes, including 3D weaving, stitching, knitting, and braiding, or by specialist techniques such as pinning and z-anchoring. Single-piece near-net-shape structures can be fabricated more easily than by using conventional ply laminates; reducing manufacturing time, material waste, and the need for bonded joints. Automated processes can eliminate the need to lay up individual plies as required for conventional laminates, thereby reducing labour costs and manufacturing time. For these reasons, 3D reinforced composites are being developed for aircraft, rocket and other high performance applications $[1,12]$.

A persisting impediment to the acceptance of 3D reinforced composites by the design community is uncertainty and conflicting data concerning the degree to which through-thickness reinforcement degrades in-plane mechanical properties, and the relative merits of competing types of through-thickness reinforcement. In fact, a large amount of empirical data has been published on the elastic modulus and strength of 3D reinforced composites for several load states, including in-plane tension, compression, bending and interlaminar shear. Fatigue life data are also available for various cyclic load conditions. These data together with micromechanical models for predicting in-plane elastic properties should provide the basis for designing and certifying 3D reinforced composites for high-performance structures. However, as Mouritz et al. [13] and Mouritz and Cox [14] highlighted for stitched composites, some studies report an improvement to in-plane mechanical properties due to stitching, whereas others find unchanged or degraded properties. Furthermore, the correlation between the stitching specifications (e.g., stitch pattern, stitch density, stitch thread diameter) and the change to in-plane properties has rarely been reported. Such incomplete and contradictory data cannot support design choices.

The large collation of data assembled for stitched laminates by Mouritz and Cox [14] approximately ten years ago revealed that the tension, compression, flexural, shear and open-hole strengths are improved or degraded by as much as $20 \%$ by stitching 
relative to those of unstitched laminates, with suspicious outliers even beyond this bound. By reference to the factors that control failure mechanisms, Mouritz and Cox [14] suggest that the substantial inconsistencies in properties might be attributed to changes in the in-plane fibre volume fraction and defects consisting of misaligned, crimped, distorted, or broken in-plane fibers. Regrettably, none of these factors are adequately examined or reported by most researchers.

In spite of the deficiencies in the published reports, the collation of data from many sources revealed some useful and scientifically interesting trends. For example, changes to the in-plane properties due to stitching were not strongly dependent on their volume content or diameter. Thus any penalty for introducing stitches does not rise if the stitch density is increased to the high levels that might be required, for example, in ballistic applications. For the data available in year 2000, the knockdown in the compressive fatigue strength for a given number of cycles to failure was found to be approximately the same as the knockdown in the static compressive strength, allowing the consequences of stitching for compressive fatigue to be estimated from a simple static test.

The purpose of this paper is to extend the research by Mouritz and Cox [14] for stitched laminates to 3D woven and pinned materials, providing a reasonably comprehensive view of their relative merits. Of special interest is whether the major trends in properties are similar or dissimilar for the three classes of composites. The paper presents a comprehensive and critical survey of published mechanical property data for 3D woven and pinned composites, along with data for stitched composites from the original study [14] and more recent publications. Although composites reinforced in the through-thickness direction by braiding, knitting or z-anchoring [e.g. 15-20] would also make interesting case studies, the unfortunately small amount of published data make it difficult to draw general conclusions and they are therefore not included. The study focuses on the in-plane properties of flat specimens and will not cover the properties of more complex shapes such as joints, stiffened panels, curved sections or structures with ply drop-offs.

In this paper the through-thickness reinforcement, whether it is a woven yarn, stitch or pin, is described by the generic term "z-binder." 
An important advantage of an inclusive survey is that insights into the mechanisms governing one material can be gained from studying the others, as will be shown in this paper. Assessments focus on the influence on the in-plane mechanical properties of increasing the volume content and size of z-binders. The survey is confined to examining the influence of z-binders on the tension, compression, flexure, interlaminar shear and fatigue properties. The few published data for other load cases, such as open-hole tension, open-hole compression and creep, are insufficient to allow meaningful comparisons between the different composites. Trends are related to the failure mechanisms for the different classes of composite. Substantial discussion of mechanisms and models of mechanisms was presented in the original study [14]. Much of this discussion remains pertinent to the new materials and therefore the original paper is recommended to the reader as a companion to this paper.

\section{FIBRE ARCHITECTURE}

The in-plane mechanical properties of 3D reinforced composites are controlled by the fibre architecture, fibre volume fraction and, especially in the case of failure mechanisms, defects. Defects include physical damage to the fibers, resin matrix, and fiber/matrix interface, and also irregularities in the fiber deployment (geometrical defects). Observations of defects in 3D woven, stitched and pinned composites show some common characteristics.

Methods for inserting z-binders by 3D weaving, stitching and pinning are described in numerous reviews [1,2,5-7,12,21-23]. Idealized schematics of the resulting architecture are shown in Fig. 1. Most fibers lie in layers in the plane of the composite, with relatively few passing through the thickness. In common 3D woven composites, the in-plane fibers are restricted to tows oriented at $0^{\circ}$ (warp) and $90^{\circ}$ (weft). In stitched or pinned composites, any lay-up of plies can be chosen. The area fraction on the mid-plane of the composite that is occupied by the through-thickness segments of the $3 \mathrm{D}$ reinforcement is typically $0.5-10 \%$. Area fractions exceeding $10 \%$ might be achieved before running into fabrication limitations, but in common skin or sheet applications, such high densities are unnecessary since $z$-binders are effective at much lower densities in suppressing delamination or sub-laminate 
buckling [e.g.3,8-11]. The common range of area fractions is achieved by spacing the through-thickness reinforcement elements $2-20 \mathrm{~mm}$ apart. The diameter of woven z-binders, stitches and pins is typically in the range $0.1-1.0 \mathrm{~mm}$. Thicker $z$-binders can be used, but tend to cause harmful distortion of the fiber architecture. Much finer reinforcements offer the possibility of minimizing damage, e.g., carbon nanotubes or single fibers, but are not included in this study since engineering data do not yet exist.

\subsection{Microstructural Defects}

Three-dimensional weaving introduces through-thickness fibers in bundles or tows, which are interlaced with the in-plane warp and weft tows and thus can penetrate the thickness of the laminate without breaking in-plane fibers. Stitches and pins, by contrast, are forced through relatively densely packed fibers, some of which are inevitably broken. To mitigate fiber breakage, stitching is almost always performed using dry fiber preforms, because the tacky resin in prepreg accumulates on the needles and causes unacceptable levels of fiber damage. Pinning is generally performed on prepreg, since the pins are difficult to control and maintain in position in a dry fiber stack; but unlike stitching, there is no carrier (needle) that must penetrate the fabric repeatedly.

The processing differences between 3D weaving, stitching and pinning can cause significant differences in the magnitude of defects. Depending on processing conditions and fiber architecture details, the least fiber breakage should be expected with weaving and the most by pinning, especially if inexpertly administered. Furthermore, 3D weaving or stitching is usually performed on computer-controlled looms and sewing machines, which promotes (but does not entirely achieve) consistent properties $[1,12,13,21-23]$. The pinning process, on the other hand, has often been performed using a hand-held ultrasonic device [1,7], which can introduce higher levels of variance. Achieving good results with pinning is now understood to require the use of a robotic insertion device [3], but much work in the literature refers to composites fabricated with hand-held devices and this must be considered in interpreting data. 
An example of fiber breakage caused by stitching is shown in Fig. 2, which is also qualitatively representative of fiber breakage due to pinning [4,13,24-26]. The broken fibers occur in small clusters in the vicinity of each $z$-binder. Although fiber breakage is common, the density of fiber breaks is rarely measured after manufacture. Herszberg et al. [27] report that under $0.5 \%$ of fibres in dry carbon fabric are broken during stitching, and Lee et al. [25] and Mouritz et al. [26] estimate that only a few percent of fibres are fractured during 3D weaving of dry glass fabric. It is expected that fibre fracture is more prevalent in pinned composites made of prepreg tape than in 3D woven and stitched composites made of dry fabric, although the percentage of fibers broken by pinning has never been measured. Higher levels of fibre fracture could occur with prepreg tape because the tacky resin matrix does not allow fibres to be easily deflected out of harm's way during pin insertion. Statistical variability in the number of broken fibers at each z-binder is expected.

Microstructural examination of 3D woven [28-32], stitched [13,33] and pinned $[4,35,36]$ composites reveals that significant distortion of the in-plane fibres occurs during weaving or insertion of stitches or pins as well as during consolidation of the composite. The distortions or geometrical defects have several similarities across the three classes of composite, including crimped and wavy in-plane fibers; crimped or misaligned $z$-binders; and resin-rich regions near the $z$-binders. Some differences can also occur, partly because of the different use of dry fibers or prepreg, partly because of different machine actions for incorporating the $z$-binders, and partly because of differences in fiber architecture. Since much evidence shows that the geometrical defects are central to mechanical performance and failure, the similarities and differences in defects often show through in engineering data [14,28].

One defect common to $3 \mathrm{D}$ woven, stitched and pinned composites is the lateral spreading of in-plane fibers in the plane of the laminate as they pass around each through-thickness reinforcement segment, which results in regions of local fiber waviness (Fig. 3). The misalignment angle of fibres measured around the $z$-binders is typically in the range $5-20^{\circ}$, regardless of whether they were incorporated using $3 \mathrm{D}$ weaving, stitching or pinning [1,4,13,28,30,31,33,35-39]. There is usually significant variability in the fiber waviness angles in a single composite specimen due to local variations in the fiber architecture. For 3D woven, stitched and pinned composites 
containing woven fabric, fiber waviness is highest when the $z$-binder penetrates near the centre of a tow and lowest when placed between tows (which is the practice with non-crimp fabrics). Because the exact positioning of the z-binders relative to individual tows is not controlled in existing stitching and pinning methods, significant scatter arises in the fiber waviness angles in the material. In contrast, pinning of prepreg tape, where the in-plane fibres are more evenly distributed, causes more uniform waviness defects.

Deflection of in-plane fibers in the $z$-direction is often termed crimping. Crimping is caused in stitched and pinned composites by punching or friction as the sewing needle or pin is driven through the material $[28,30,36]$. An example of such crimp surrounding a $z$-binder is shown in Fig. 4. Fiber crimping is also created in 3D woven and stitched composites by indentation pressure under the segments of the $z$-binder yarns that lie along the outer surfaces of the laminate during consolidation in a pressurised mould. Fig. 5 shows a schematic of this effect that is representative of observations on a 3D woven composite [28]. The severity of crimping due to surface segments appears to be similar for $3 \mathrm{D}$ woven or stitched composites, although quantitative measurements are lacking.

The displacement of fibers by 3D weaving, stitching or pinning can cause significant variations in the fiber volume fraction; either locally near individual $z$-binders or as a material average. Small increases (typically less than 10\%) to the average fiber content of stitched composites have been reported due to taut stitches drawing the plies together [40]. On the other hand, if the material is not constrained globally, its gross in-plane dimensions and thickness may increase due to the presence of the $z$ binders, allowing fiber spreading. Consequent decreases in the fiber volume fraction appear to be most serious with pinning. For example, Fig 6 shows measurements of the percentage change to the average fiber content of a carbon-epoxy tape composite with increasing pin content when the pins were inserted in constrained and unconstrained conditions. The fiber content decreases at an approximately linear rate with increasing pin content due to thickening of the laminate. In the absence of constraint, a relatively modest pin content (4\%) may cause a large reduction in the average fibre content $(>10 \%)$ [4,36]. Fiber dilution occurs due to swelling of the 
prepreg to accommodate the pins and the resistance imposed by the rigid pins against consolidation during laminate curing [36].

Crimping of the $z$-binders themselves is another form of defect that can arise in 3D woven and stitched composites when a preform is heavily compacted in a pressurised mould (e.g. Fig. 7) [1,14,29,41]. Such effects do not occur in pins because of their high axial stiffness. However, pins can exhibit an alternative defect under compaction pressures: they can become misaligned from the vertical direction during insertion and consolidation, as shown in Fig. 7b. For a nominally vertical pin, total final rotation of $10-15^{\circ}$ appears to be common with current fabrication practices $[4,36]$.

\subsection{Predicting and Measuring Defects}

Models for calculating the elasticity and strength of 3D composites require accurate specification of the type and magnitudes of defects produced during manufacture. Models that predict the nature of defects for given manufacturing conditions and material choices (as distinct from models that predict the consequences of defects on composite behaviour) are gradually being developed for textile performs. There has been some progress on modelling defects in 3D woven composites [42], but not for stitched or pinned materials. Experimental measurements of defects also remain very imperfect. Measurements to date are typified by the sectional images of Figs. 2 - 4, $7 \mathrm{a}$, and $7 \mathrm{~b}$, which are insufficient to quantify the deployment of fibers in three dimensions. To fill out 3D defect data by serial sectioning is tedious and an inadequate approach to obtaining the statistics of multiple defects. A more promising approach is X-ray computed tomography, which has shown outstanding ability to probe internal structure and failure mechanisms in polymer matrix composites and $3 \mathrm{D}$ woven ceramic composites (Fig. 7c), yielding the information that is critical for developing accurate failure predictions [32,43-47].

But even when rich 3D data are available, rendering them into mathematical representations that are suitable input for computational simulations will be much easier and more rational if the defect data are fitted to mechanics-based predictions of the defects. Such predictions, which can supply appropriate functional forms for the 
fiber geometry in defects, require modelling of the mechanics of the process of incorporating the $z$-binders.

In the processing of $z$-binders, fiber preforms undergo strains of the order of unity at the local level while subject to triaxial stress fields. This challenging modelling problem remains delayed by the absence of accurate constitutive laws for fiber bundles under triaxial stress states. Almost all tests for obtaining constitutive laws to date, including the large body of literature on the drape of textiles, have dealt with $2 \mathrm{D}$ fabrics loaded peripherally, with negligible through-thickness loads. However, experiments reveal that the mechanisms of deformation under combined in-plane shear and through-thickness compression are different to those in draped fabrics [48]. For example, in draped fabrics, the tows or other fiber bundles rotate past one another by a scissoring action where they cross-over one another. Through-thickness compression suppresses this mechanism by raising friction at the crossovers and deformation occurs mainly by large-strain shear of short segments of fiber bundles between crossovers (Fig. 8). The constitutive response of fiber bundles in such a preform is governed by friction, which depends strongly on the magnitude of the through-thickness compressive stress [48]. However, the details are not easily deduced from experiment, because it is not easy to recreate the stress conditions that exist within a 3D preform in a single fiber bundle; and the analysis of an entire preform is complicated by strong non-linearity.

Until the research community addresses the problem of fully characterizing defects by combined theory and measurement, the interpretation of the influence of defects on measured property data can only explain qualitative trends.

\section{STANDARDIZED PRESENTATION OF DATA}

\section{Equivalent 2D Laminate}

A useful method of standardizing property data for composites with through-thickness reinforcement is to normalize them against data for what have been called "equivalent" 2D laminates. For the purposes of the present collation, the ideal equivalent 2D laminate differs from the 3D composite only in the absence of the $z$ binders; being the same in all other aspects of fiber architecture. The equivalent 2D laminate should have the same fiber volume fraction of in-plane fibers (i.e., fibers 
other than those in the z-binders); but variance in in-plane fiber volume fraction cannot always be avoided.

In the case of pinned laminates, since the pinned products are formed with tape prepreg, the equivalent 2D laminate is simply a tape laminate having the same ply lay-up. In the case of stitched laminates, the stitched products studied in the original source study were formed by stitching a variety of stacked 2D preforms, with most being 2D plain weaves. The equivalent $2 \mathrm{D}$ laminate therefore consisted of a laminate of the same type of 2D fabric stacked in the same lay-up as in the stitched product. In the case of $3 \mathrm{D}$ weaves, the choice of an equivalent 2D laminate is not as satisfactory: if the z-binders are omitted from a 3D weave, the remaining in-plane warp and weft tows are not easily handled or consolidated into a composite. Therefore, the equivalent 2D laminate was usually defined as a stack of 2D plain woven plies that generated the same total counts of in-plane load-bearing fibers as in the $3 \mathrm{D}$ woven composite.

For all the property data reported here, the original source articles presented data for both the 3D composite and the equivalent 2D laminate defined as above. Where original sources did not publish data for the equivalent 2D laminate, the data were not used. All data are presented here as the ratio of the datum for the $3 \mathrm{D}$ composite to the datum of the equivalent $2 \mathrm{D}$ laminate that were presented in the source article.

To isolate changes due to the $z$-binders and allow consistent comparison of different types of through-thickness reinforcement, compensation must be made for any differences in the volume fractions of the in-plane fibers in the equivalent $2 \mathrm{D}$ laminate and the $3 \mathrm{D}$ composite. Ideally, the two composites should have the same fiber volume fractions, but the realities of processing make this difficult to control perfectly. Data from most source articles are used under the assumption that the inplane fiber volume fractions were identical for the 2D and 3D composites tested, but this may not always be true, as discussed below.

The definition of equivalent 2D laminate used here differs from the "equivalent tape laminate" suggested in the 1980's as a normalization for 3D composite data (e.g., NASA Langley's Advanced Composites Technology program, 1987-1995 [49]). The 
equivalent tape laminate was always formed as a 2D lay-up of unidirectional tape plies. The present definition is preferred because it isolates effects due to the zbinders alone. For example, if a stitched laminate is formed by stitching 2D plies of woven fabric, then differences relative to the equivalent tape laminate will include differences arising between those 2D fabric plies and unidirectional plies as well as differences due to the effects of stitching. The effects due to stitching alone would be impossible to identify.

\section{Quantification of z-Binder Content}

(i) Stitched Composites. Most property data published for stitched composites are plotted against the number of stitches per unit area, which is a controlled manufacturing parameter. Alternative measures are the area fraction of stitches on the mid-plane of the composite or the total volume fraction of stitches. However, most stitching studies do not express the stitch content in volume percent and provide insufficient data for this to be deduced from the stitch area density. For this reason, the in-plane properties of stitched composites are plotted against the area fraction of stitches (i.e. number of stitches per unit area).

(ii) 3D Woven Composites. 3D woven composites are usually defined in terms of the total volume fraction for $z$-binders, because this is controlled in manufacture. With 3D weaves, the area fraction of $z$-binders is not easily deduced because of insufficient detail about weave architecture, yarn denier, etc., in the original works. Therefore, data for 3D woven composites are plotted against the percentage volume content of $z$-binders.

(iii) Pinned Composites. The amount of $z$-binders in pinned composites is usually expressed as the percentage volume fraction, and this measure is used here.

\section{Restriction on Data Presented}

Not all the data available for different properties are presented. Data are omitted when information on the z-binder content was insufficient or data are not presented for the equivalent 2D laminate in the original publication. 


\section{YOUNG'S MODULUS}

\section{Trends in collated data}

The most important measure of in-plane stiffness is Young's modulus, $E_{1}$, in the direction of the dominant fiber orientation. Variations in elastic modulus for stitched composites were discussed in detail by Mouritz and Cox [14]. Similar conclusions are reached here for 3D woven and pinned composites. Figures $9-11$ show tension modulus data for 3D woven composites [25,50-54], and tension, compression and flexural moduli data for pinned [36,55-58] and stitched composites [59-67]. While published data exist for the compression and flexural moduli of 3D woven composites, there are none for the equivalent 2D laminate. The data in Figs. $9-11$ are plotted as normalized Young's modulus values, $E_{1} / E_{0}$ where $E_{0}$ is the value for the equivalent 2D laminate, against $z$-binder content. The 3D woven materials include orthogonal and angle interlock weaves made with carbon (CFRP), glass (GFRP) or Kevlar (KFRP) fibres. Data for stitched composites represent a diverse range of materials stitched with various thread materials. Data for pinned composites are for carbon/epoxy prepreg laminates reinforced with Z-fibers ${ }^{\circledR}$ made of carbon/bismaleimide. Such a diversity of materials allows a general comparison between the different types of 3D composites.

The data for the 3D woven and stitched composites show similar statistical trends for all three moduli (tension, compression, and bending), whereas the pinned composites show a different trend. For the 3D woven and stitched composites, the throughthickness reinforcement can apparently either lower [40,51,52,59-60,64,66-71] or increase [25,51-52,66] Young's modulus (data scattered below and above unity). In contrast, Young's modulus is reduced or occasionally unaffected by pinning, but never enhanced $[7,36,55-58,67,72]$.

Apart from a few outliers, the data for 3D woven and stitched composites fall in the range $0.8<E_{1} / E_{0}<1.2$, with the deviance reasonably consistent over a wide range of $z$-binder contents. No statistically significant trend exists between the modulus and $z$ binder content. For cases plotted in Fig. $9-11$ with $z$-binder content near 20\%, the normalized modulus might be expected to decrease because the volume fraction of inplane fibers must be reduced significantly to accommodate the $z$-binders. That no such trend appears in Figs. 9 - 11 might simply be due to the low statistical 
significance of the few pertinent data; and the point is usually moot, because the $\mathrm{z}$ binder content in 3D woven and stitched composites rarely exceeds $5 \%$ by volume (equivalent to a stitch content of approximately 0.1 stitches $/ \mathrm{mm}^{2}$ ). For pinned composites, the normalized Young's modulus does decrease approximately linearly with increasing z-binder content [36,55-58,67,72]; and some of this decrease correlates with reduced fibre volume due to swelling.

Recent research also shows Young's modulus decreasing linearly with increasing pin diameter $[36,56,57]$. However, the modulus of 3D woven and stitched composites is not dependent directly on the $z$-binder diameter (e.g., data presented in Fig. 12).

\section{Candidate mechanisms}

It is impossible to identify with certainty the reason for the variance of individual modulus data sets, but it is useful to consider plausible causes. The factors detailed by Mouritz and Cox [14] for stitched composites remain pertinent. Increases in the normalized elastic modulus, i.e., relative to the equivalent 2D laminate, are almost certainly due to increases in the in-plane fiber volume fraction. The most likely cause of increased in-plane fiber volume fraction is the process of introducing stitches or woven z-binders under tension, which can debulk or consolidate fiber performs. Careful quantification of local and average fiber volume fractions and their relation on processing parameters would be immensely valuable to determining their influence on changes to the elastic modulus. Modulus variations of $\sim 10 \%$ due to compaction seem plausible, but where higher increases appear in Figs. 9b, 10a, or 11a, the validity of the data must be doubted, in the absence of any accounting in the original papers.

Decreases in the normalized elastic modulus can be attributed to either reductions in the in-plane fiber volume fraction or waviness and crimping of in-plane fibres (geometrical defects of the kinds described in Section 2). Fibre breakage or resin-rich zones should not strongly affect global elasticity. Fiber volume fraction can be reduced by increases in the laminate thickness or spreading of the in-plane fibers as they pass around $z$-binders. Chang et al. [36,56,57] and Mouritz [58] recently showed that the reduction to the elastic modulus of pinned composites correlates directly with the reduction in their fiber volume content. The fiber content is reduced by swelling of the composite to accommodate the pins and the resistance stiff pins impose against 
preform compaction during curing. However, research into 3D woven and stitched composites has failed to prove that the reduction to the Young's modulus is caused, at least in part, by local and average changes to the fiber content. The effect of such changes would be easily calculated, but unfortunately the necessary fiber volume fraction data have not been reported in the majority of published studies.

Modulus reduction in a stitched laminate due to the crimping of in-plane fibers is implied by the data of Roth and Himmel [73], who found a greater reduction in inplane modulus in the direction normal to the stitching direction than parallel to it. Crimping of in-plane fibers by the surface segments of stitches will appear normal to the stitching direction only and is therefore a candidate source of the observed anisotropy. However, controlled experimental studies examining the effect of fiber crimp (by changing the crimp angle) on the stiffness of 3D composites have not been performed. While several studies have measured the in-plane fiber waviness angle around $z$-binders $[13,36]$, measurements of the through-thickness fiber crimp angle have not been reported. Both in-plane and through-thickness fiber angles around $z$ binders must be measured to analyse the effect of local changes in fiber waviness on the Young's modulus.

Various theoretical studies have estimated the knockdown in Young's modulus due to in-plane fiber waviness in 3D woven, stitched and pinned composites [34,74-86]. Most theoretical studies assume that fiber waviness angle is identical at every $z$-binder within the composite, but in reality there are significant variations in fibre angle (typically over the range 5-20 ${ }^{\circ}$. Many modelling studies ignore the effect of out-ofplane fiber crimp and local changes to the fiber volume content on the elastic properties. Despite these shortcomings, good agreement is generally seen between the statistical ranges of measured and calculated knockdowns in stiffness. However, some caution is due before claiming victory. Three unusually comprehensive studies of the stiffness of 3D woven [74] and stitched composites [73,78], in which care was taken to measure fiber volume fractions and the details of irregularity in the fiber architecture, show that correlating one particular phenomenon with measured stiffness variations is extremely difficult. The influence of a single factor, such as fiber volume fraction, in-plane fiber crimp, fiber waviness or the contribution of the surface segments of a stitch or woven $z$-binder is not easily distinguished in the noise of 
experimental data. The goal of assuring that the variance of Young's modulus will remain within specified limits has not been reached because of inadequate treatment of the statistics of different types of defects. This state continues to impede the use of 3D composites in stiffness-critical structures.

Because Young's modulus for 3D woven and stitched composites does not tend to decrease progressively with increasing $z$-binder content, it should be possible when designing impact tolerant structures to raise the $z$-binder content as required for damage resistance without incurring an increasing penalty in stiffness. The modulus of pinned composites does decrease steadily with increasing $z$-binder content, and therefore any improvement to impact damage tolerance gained with high density pinning will incur a loss in stiffness. However, the loss in modulus with increasing pin content is usually moderate, particularly for composites with a quasi-isotropic layup [36,56-58]. Therefore it is possible to achieve a high level of damage tolerance without degrading the elastic properties by more than $10 \%$.

\section{TENSILE STRENGTH}

\section{Trends in collated data}

As with stiffness, tensile strength data for 3D woven and stitched composites vary over whether the strength is improved [59,60,63,66,88-90], unchanged $[25,27,66,88,91]$ or degraded $[52,61,64,66,67,89]$ by the $z$-binder reinforcement, while the tensile strength of pinned composites is always degraded [5,7,3655,67,72]. The normalized strength, defined as the tensile strength of the $3 \mathrm{D}$ composite, $\sigma_{\mathrm{t}}$, divided by that of the equivalent $2 \mathrm{D}$ laminate, $\sigma_{\mathrm{t}}^{(0)}$, is plotted in Fig. 13. The extension here of the data compiled in Mouritz and Cox [14] for stitched composites to include 3D woven and pinned composites reveals contrasting dependence on the $\mathrm{z}$ binder content. For 3D woven composites, the data suggest a modest decrease in tensile strength with increasing $z$-binder content, although with large statistical scatter; for stitching, no statistically significant relationship trend exists between the normalized strength and either the stitch content or diameter; and, for pinning, a relatively strong decrease is seen with pin content, with modest statistical scatter. The pinned composites also show a strong dependence on relative weights of in-plane 
fibers of different orientations, with the loss in strength increasing with the percentage volume fraction of load-bearing $\left(0^{\circ}\right)$ fibers.

Values for the stitched composites are within the range 0.8 to 1.2 over a wide range of stitch contents, with the exception of a few outlying data points. This is numerically the same range as that found for Young's modulus (Figs. 9 - 11). Chang et al. [36] and Mouritz et al. [72] measured a linear relationship between reduced tensile strength and increased pin content, but the correlation coefficient of this relationship is lower for the data in Fig. 13c because of the differences among the collated studies in the composite materials, the fiber lay-up patterns and, of particular importance, the quality of the z-pinning process, which determines the presence of defects.

\section{Candidate mechanisms}

Reductions to the tensile strength of 3D woven, stitched and pinned composites can be attributed to geometrical defects, such as waviness and crimping of in-plane fibers. Strength may also be lowered by fiber breakage during processing, which has been reported for 3D weaving [24-26], stitching [13] and pinning [35,67]. The differences in the trends shown in Fig. 13 for the three classes of 3D composites remain unexplained, although one mechanism can be suggested as follows [36]. Fabric preforms used in 3D woven and stitched laminates are dry when the $z$-binder is inserted, and most fibres are pushed aside into the void space between the tows. Pins are inserted into tacky prepreg, which adheres to the pins during insertion and might therefore cause greater fibre damage. A pinned composite would therefore have lower tensile strength (normalized against that of the equivalent 2D laminate) than either a $3 \mathrm{D}$ woven or stitched composite. However this mechanism does not explain why the lowering of strength should rise with pin density (as the data show) but not with stitch density and only weakly with woven $z$-binder density. Tensile strength can be determined by a single defect, such as a weak region next to a single $z$-binder. Increasing the density of defects does not necessarily lower tensile strength below that of a material containing just one defect.

No mechanism has ever been directly observed for the instances of increased tensile strength in 3D woven and stitched composites. While once again the absence of details in many of the original reports precludes confident inferences in any particular 
case, a plausible general mechanism for strength increase is compaction of the $3 \mathrm{D}$ woven and stitched preforms by the tension in $z$-binders during processing. In contrast, the fiber content cannot be increased by pinning, which may explain why the tensile strength is never increased with this reinforcement technique.

Other aspects of failure mechanisms in pinned composites are as follows. Postmortem examination of unidirectional composites containing pins shows multiple splitting cracks running the length of the specimen and spaced commensurately with the pin spacing $[36,56]$. The ligaments of material that are bounded by the splitting cracks appear to rupture at the pin locations. Because failure is catastrophic, even under displacement control, whether the splitting cracks or the tensile ruptures occur first is unknown; the two mechanisms may well interact dynamically (influenced by inertia) during the failure process. One driving force for splitting can be deduced qualitatively from considering the geometrical defect of Fig. 3. The deviation of nominally aligned in-plane fibers as they pass around a pin creates local transverse tension at location T under uniaxial far-field tension (load axis as indicated in Fig. 3). The reason for this is that far-field tension tends to straighten the fibers, so that they are drawn apart in the regions between the pins. The transverse tension thus developed can initiate splitting cracks. A second driving force for splitting would arise following the rupture of a ligament of composite material lying between rows of pins, should rupture precede splitting. When such a ligament fails, the load in the ligament at the rupture site must fall to zero and then recover to the far field value by shear load transfer between the ligament and the surrounding laminate. These shear stresses will cause splitting of the ligament from the laminate extending away from the rupture site. The rupture of ligaments is presumed to follow from the rupture of a critical number of fibers in the vicinity of a pin.

Two mechanisms can account for the fact that ligament rupture is strongly correlated with the location of pins. 1) The action of pin insertion causes some degree of localized fiber breakage. 2) Misalignment of in-plane fibers near a pin (Fig. 3) will give rise to local axial shear stresses under aligned far-field tensile loads, which can cause plastic strains (irreversible matrix deformation) within the misaligned bundles [94]. Stitched and 3D woven composites show similar geometrical defects to pinned materials, and therefore similar mechanisms may control tensile failure. 
While the preceding observations of mechanisms are valuable background, they do not yet explain the trends in the normalized strength data. Pinpointing the source of the trends will require experimental and theoretical accounting of the geometrical defects (fiber crimp, fiber waviness, etc.) and physical defects (broken fibers). Variations in the local fiber packing density and the maximum fiber misalignment as the $z$-binder spacing is varied, both in the longitudinal and transverse directions, and as the $z$-binder diameter is varied must be quantified. The extent of fiber breakage during dry preform processing (for 3D weaving and stitching) and prepreg processing (for pinning) must be determined. Without a good understanding of the factors that govern tensile strength, design and manufacture of damage tolerant structures must be unnecessarily conservative.

As with Young's modulus, the data reveal that 3D woven and stitched composites can be reinforced with a high $z$-binder content for high impact damage tolerance without suffering a greater loss in tensile strength than would occur at a lower $z$-binder content. In contrast, existing data show that increasing the impact resistance by raising content of z-pins leads to ever-decreasing tensile strength as the pin content rises. This difference between woven or stitched and pinned laminates may well be related to the in-plane fibre architecture, rather than differences in the through-thickness reinforcement per se. Both woven and stitched composites are made using woven fabrics, in which in-plane fibers possess inherent crimp, with crimp angles of $2-10^{\circ}$ depending on the tow size and weave pattern. Therefore, relative changes to the fibre alignment (crimp, waviness) caused by the through-thickness reinforcement may be less noticeable than in pinned laminates, where the control material (tape laminate) contains straight (uncrimped) fibres. There has been no published research into the in-plane properties of woven composites that have been pinned, which would test this speculation.

\section{COMPRESSIVE STRENGTH}

\section{Trends in collated data}

Figure 14 shows the compressive strength of 3D woven and stitched composites can be improved $[52,59,92]$ or degraded $[33,52,59,61,62,68-71,92,95-101]$ by the $z$-binder 
reinforcement or remain unchanged [60]. There are no reported cases where pinning has improved compressive strength $[7,35,58,67,102]$.

For 3D woven composites, the normalized compressive strength data show large scatter and no statistically significant trend with the $z$-binder content. For stitched laminates, data indicate a broad distribution of compressive strengths at low stitch concentrations, with a statistically significant indication of increased strength; and a universal decrease of strength at higher stitch concentrations (Fig. 14b). The stitch diameter (denier) has little influence. For pinned laminates, the compressive strength data have a similar trend to that for other in-plane properties, decreasing consistently with increasing volume content and diameter of the pins.

\section{Candidate mechanisms}

The knockdown in compressive strength relative to the equivalent $2 \mathrm{D}$ laminate depends first of all on whether delamination is suppressed by the $z$-binders, but this is almost always true at common stitch or woven $z$-binder densities [14,28]. With delamination suppressed, kink formation will be the dominant failure mechanism. The reader is referred to the compression failure mechanism map in Mouritz and Cox [14].

Stitched laminates When delamination is suppressed, the potential exists for the compressive strength to be raised relative to that of the equivalent $2 \mathrm{D}$ composite. This is one possible explanation of the preponderance of data with relatively high strength in Fig. 14b at stitch densities of $0.04 \mathrm{~mm}^{-2}$ or less. Another possible source of elevated strength is compaction of the in-plane fibers by stitching, which can raise the fiber volume fraction.

The introduction of stitches causes geometrical defects - the misalignment of in-plane fibers as they pass around a stitch - which trigger kink band failures in compression. The compressive stress required for kinking decreases with increasing misalignment angle [104] and therefore kink initiation occurs first at the most heavily distorted region around a stitch. The kink bands that form are typically only $100-200 \mu \mathrm{m}$ wide [104], which is much less than the spacing between individual stitches of $2-20$ 
mm. Thus the first kink band to form will develop independently of any kink bands that may form at neighbouring stitches because the spacing is much larger than the kink band width. This would suggest that compressive strength should be independent of the $z$-binder content, which is approximately the case for those data for stitched materials that do show decreased strength.

Thus consideration of mechanisms suggests that the data for stitched composites can be partitioned into two groups: the first, traversing all stitch densities, shows strength decreased by an approximately constant amount; and the second, confined to lower stitch densities, shows significant increases in strength. This partitioning implies that at lower stitch densities, the misalignment defects caused by stitching might be less severe (with some exceptions), allowing the gain in strength from delamination suppression to be the dominant effect, while defects in the second set of cases are sufficient that strength is degraded. Quantitative assessment of geometrical defects would help establish the correlations between defects and strength. A major opportunity exists to use modern X-ray computed tomography to image details of fiber alignment defects and the associated mechanisms of damage evolution [e.g. 105106]. The data of Fig. 14b imply that the potential gains from controlling defects by controlling processing parameters are substantial.

Woven and pinned composites Similar mechanisms of delamination suppression and kinking at geometrical defects govern the compressive failure of woven and pinned composites [28,107]. However, the collated data suggest significant differences in how the prevalent mechanism varies with $z$-binder content for the case of stitching. For 3D woven composites, which apparently always fail by fiber kinking $[28,107,108]$, cases of increased and decreased strength occur at all values of $z$-binder content (Fig. 14a).

Recent research into the compressive failure of pinned composites has showed that kink band formation occurs at a localized region where the fibers are most heavily crimped by a single pin [35,103]. Pinned composites fail once the kinking process becomes unstable, with collapse of the fibres by microbuckling along a transverse row of pins [58]. For pinned composites, in spite of the suppression of delamination, the degrading influence of kink-triggering defects is always dominant (Fig. 14c). 


\section{FLEXURAL STRENGTH}

Flexural strength is one of the least studied in-plane properties of 3D composites. While substantial flexural strength data exist for stitched composites [14] and some for pinned composites [56,57], there are few data for 3D woven materials [52]. It is therefore difficult to determine whether woven $z$-binders affect flexural strength in the same degree as stitches or pins. More research is needed before 3D woven composites can be used in an optimal manner in structures subjected to high bending loads, such as beams and deck plates.

\section{Trends in collated data}

Figure 15 shows plots of normalized flexural strength $\left(\sigma \sigma_{\mathrm{o}}\right)_{\mathrm{F}}$ against $z$-binder content for stitched and pinned composites. For stitched laminates, trends have some similarity to those for compressive strength: the data indicate benefit at low stitch concentrations $\left(\leq 0.04 \mathrm{~mm}^{-2}\right)$ and either little effect or some decrease of strength at high stitch concentrations. As with the other in-plane properties, the flexural strength of the stitched composites is independent of the density and diameter of the stitches. The normalized flexural strength is usually within the range $0.8-1.2$ over the range of stitch contents. There are a few cases when stitching appears to have increased the strength by more than $20 \%$, although these data (all from a single study) must be treated with caution in the absence of a description of strengthening mechanisms by the authors [66].

For pinning, flexural strength shows a steady decline with increasing pin content (Fig. $15 \mathrm{~b})$, which is consistent with observations for the other mechanical properties. The flexural strength also decreases with increasing pin diameter.

\section{Candidate mechanisms}

Stitched composites Echoing the arguments for compressive strength, the modest improvements in flexural strength due to stitching (up to 20\%) are due either to delamination suppression coupled to relatively weak geometrical defects or higher fiber volume fractions of in-plane fibers. Since cases of increased strength are confined, as for compression strength, to low stitch densities, one infers again that the 
degree of misalignment in geometrical defects may increase with stich density. Unfortunately, direct observation of the failure mechanisms of stitched composites under bending loads is limited [40]. For cases of decreased strength, Mouritz and Cox [14] suggest similar mechanisms that cause degradation of tensile strength (e.g. clusters of broken fibers) and compressive strength (e.g. fiber crimping) as described above.

Pinned laminates Chang et al. [57] recently performed the only published study into the mechanisms controlling the flexural strength of pinned bias [0/90] composites. Carbon-epoxy laminates without pins failed under bending by delamination cracking. Delamination failure was suppressed in the presence of pins, and instead the composite failed by fibre fracture (on the tension-side of the flexural specimen) and transverse rupture along the pin rows.

\section{INTERLAMINAR SHEAR STRENGTH}

\section{Trends in collated data}

Figure 16 shows interlaminar shear strength data for 3D woven, stitched and pinned composites over a range of $z$-binder contents. Substantial data are available for 3D woven and stitched composites [50,51,61,68,93,109,110], but little for pinned materials [111]. The data are normalized by the strength of the equivalent 2D laminate tested under identical conditions. Almost all of the data have been determined using the short beam shear test. The data show that the interlaminar shear strength for $3 \mathrm{D}$ woven and stitched composites is usually enhanced or degraded by less than $20 \%$. The only strength data to greatly exceed this limit are for a 3D woven composite with the exceptionally high $z$-binder content of $18 \%$, whose strength is enhanced by about $50 \%$. As with other mechanical properties, interlaminar shear strength data for 3D woven and stitched composites show no clear dependence on the content or diameter of the $z$-binder. Most studies report improvement $[50,68,112]$ but in some cases the strength is degraded or remains unaffected [51,61,93,112]; overall the collated data suggest a gradual increase in strength with z-binder content, with a relatively weak statistical correlation factor (Figs. 16a and 16b). The interlaminar shear strength of the pinned composites, like their other properties, decreases steadily with increasing $z$-binder content [111]. 


\section{Candidate mechanisms}

A 2D laminate with a brittle polymer matrix will almost always fail in a short beam shear test by a single interlaminar shear crack (delamination crack) at the mid-plane of the specimen. Failure of 3D woven, stitched and pinned composites is more complex, with mechanisms including delamination and also failure of in-plane fibers (often near the specimen surface). Thus failure of crimped in-plane fibers near the specimen surface was observed by Mouritz [110,111] in stitched or pinned composites and identified as the source of degraded interlaminar shear strength. The same mechanism may be active in cases of degraded strength in other 3D woven composites, but the evidence is incomplete. Cases of enhanced strength are probably mainly due to the effects of the through-thickness reinforcement, in first delaying and then bridging delamination cracks [e.g. 14].

For the mechanism of interlaminar shear cracking, two events of engineering interest arise. First is the process of initiating and propagating a delamination crack, which can generally be done without failing the $z$-binders. The crack propagation is often stabilized by the bridging action of the $z$-binders [113]. The $z$-binders also tend to suppress crack opening, so that the crack propagates in nearly pure mode II conditions [114,115]. The crack sliding displacements are relatively small during crack propagation (of the order of a few hundredths of a mm). The second engineering event is ultimate failure, for which the $z$-binders must rupture, except possibly in the case of pins, and pull-out of the laminate. Ultimate failure is associated with large crack sliding displacements, typically $\sim 0.5 \mathrm{~mm}[116-118]$.

Many of the mechanisms of shear deformation in and around individual $z$-binders are very similar in 3D woven, stitched and pinned composites [116-119]. For the nearly pure mode II cracks found in interlaminar shear tests (with opening suppressed by the $z$-binders), the principal mechanisms in common are: debonding of the $z$-binder from the laminate and sliding of the z-binder along its axis; internal irreversible shear deformation of the $z$-binder culminating in multiple splitting cracks along the fiber direction within the $z$-binder; and plastic deformation of the laminate adjacent to the $z$-binder, which allows the $z$-binder to deflect laterally. The composite deforms in most cases with a remarkable absence of cracking and spalling. 
For determining ultimate shear strength, pinned and 3D woven or stitched composites are distinguished mainly by the difference in the boundary condition at the outer surfaces of the specimen. The axial stress within a pin must come to zero at the ends of the pin, whereas the axial stress in a stitch or woven $z$-binder can be transferred into segments of the $z$-binder that turn around continuously on the outer surface of the laminate. A stitch or woven $z$-binder can never pull-out until it has ruptured.

Interestingly, this major difference in failure mechanism is not obviously reflected in superiority of 3D woven or stitched composites in ultimate interlaminar shear strength. Pins of similar area fraction on the specimen mid-plane (delamination plane) appear to be roughly equally effective in sustaining bridging loads to woven $z$ binders or stitches. The reason for this may be looked for in details of the mechanism of load transfer between the pins and the laminate. Experiments on miniature specimens containing single pins [118] and modelling [120] show that, where a pin has begun to deflect laterally through the laminate, strongly enhanced friction arises between the pin and the composite. The load required to pull the pin out of the laminate is thereby significantly increased over that required to pull a pin out in mode I (zero lateral deflection). This enhancement of friction (or snubbing effect) leads to ultimate loads for pins in mode II that are similar to those measured for stitches of equal diameter (Fig. 17) [116,118]. Further, the snubbing effect is greater when the pin is inclined so as to resist the shear displacement. In this case, friction can be so strong that the pin ruptures rather than pulling out $[118,120]$.

In regard to delamination crack propagation, much study has been made of the inhibiting action of $z$-binders $[9,113,117,120-126]$. Some of the differences and similarities that might be expected among 3D woven, stitched and pinned composites are indicated by models (e.g., [120]) and experiments. For the small crack displacements associated with crack propagation, the $z$-binders provide a stiffer resistance, and therefore higher crack propagation stress [113], if they are aligned more closely with the shear displacement direction. Because this effect can be substantial, systematic experiments to compare crack propagation in laminates with different forms and orientations of $z$-binders would be very timely. 
A further experimental challenge may be found in explaining the observation that interlaminar shear strength does not appear to increase with $z$-binder density, when it is determined by short beam shear tests. A simple view of the action of $z$-binders as bridging entities following passage of a delamination crack would suggest that the tractions they sustain and therefore the total load at ultimate should increase with their density. One possible explanation of this is the small specimen size used in the short beam shear test. The test specimens are generally less than $20-30 \mathrm{~mm}$ long and 10 $\mathrm{mm}$ wide and therefore contain a small number of $z$-binders, since these are typically spaced 5-20 mm apart. Further, the loading of the $z$-binders will be non-uniform because the stress field of the specimen is non-uniform, so that there may be a tendency for them to fail singly rather than together: the load on each $z$-binder rises not far from linearly with its displacement and therefore those most displaced will carry most of the load. The short beam shear test may be poorly designed to test the effects of increasing $z$-binder density over all interesting ranges. Interlaminar shear tests using another test method with a larger specimen gauge area would be of interest.

\section{FATIGUE}

The fatigue properties of 3D woven [87,91,127,128], stitched [88-90,97,129-133] and pinned [36,56-58] composites have been measured in sufficient detail to identify some useful trends in the influence of $z$-binder reinforcement on fatigue life. The majority of fatigue studies report reductions to the fatigue strength and fatigue life (number of load cycles to failure) due to $z$-binders. With the exception of one study [90], the fatigue properties of 3D woven, stitched and pinned composites are consistently lower than their equivalent $2 \mathrm{D}$ laminate. This behaviour is different to the static properties of 3D woven and stitched composites, with many of these materials having increased stiffness or strength (Figs. 9-15). The static and fatigue properties of pinned composites always show a reduction, which increases with the pin content and pin diameter [36,56-58].

The fatigue life (S-N) curve for most 3D composites has a similar slope and shape as the equivalent 2D laminate $[57,70,71,89,90,129,131]$. For example, Fig. 18 shows that the fatigue life curves for stitched and pinned composites and the equivalent $2 \mathrm{D}$ 
materials are parallel; the only significant difference being the reduction in monotonic strength caused by the $z$-binders. In these cases, the fatigue life curve for the $3 \mathrm{D}$ composite can be predicted by simply shifting the $S-N$ data for the equivalent $2 \mathrm{D}$ laminate down the stress axis by an amount equal to the difference in the monotonic strengths of the $3 \mathrm{D}$ and $2 \mathrm{D}$ materials. When the fatigue strengths $\left(\sigma_{f}\right)$ of the $2 \mathrm{D}$ and $3 \mathrm{D}$ composites are normalized against their respective monotonic strengths $\left(\sigma_{o}\right)$, the fatigue life curves for the two materials are identical (as shown in Figs. 18c \& d).

While this knock-down behaviour occurs for many 3D composites, significant exceptions exist $[36,58,88,91,128,133]$, exemplified by the non-parallel curves in Fig. 19 for some other stitched and pinned materials. Available evidence suggests that the knockdown rule is accurate only when the fatigue failure mechanism is similar in the 2D and 3D materials. The rule fails when different fatigue mechanisms operate.

The slope of an $S-N$ curve indicates the rate at which fatigue is bringing about a fractional reduction in strength. When fatigue data for the $3 \mathrm{D}$ composite and its equivalent 2D material exhibit the same slope (as shown in Fig. 18), it can be inferred that the $z$-binders do not change the rate of fatigue degradation of strength. The only influence of the $z$-binders is their knock-down in the fatigue strength by an amount equal to the knock-down in monotonic strength. In these cases, the $z$-binders do not change the fatigue mechanism controlling residual strength. If, on the other hand, the slope of the $S$ - $N$ plot is changed by the z-binder (e.g. Fig. 19), it is suggested the acceleration or deceleration of fatigue is caused by a change in mechanism. Unfortunately, many fatigue data have been published without details of mechanisms, obscuring the question of whether the $z$-binders will change the slope of the fatigue life curve because of a change in mechanism. The data by themselves show cases when stitching or pinning has not changed the slope [57,70,71,89,90,129,131], and other instances when the slope is changed [36,58,88,91,128,133]. The currently unpredictable nature of fatigue life is due mostly to an incomplete understanding of mechanisms.

\section{Trends in collated data}


$3 D$ woven composites. The fatigue properties of $3 \mathrm{D}$ woven composites have been determined under tension [91,128], compression [87] and flexure [127] cyclic loads, although these remain the least studied of the three classes of 3D composite materials. Because of the difficulty in defining and fabricating a $2 \mathrm{D}$ woven laminate that is equivalent to the $3 \mathrm{D}$ woven material, only a few studies have compared the fatigue life of 3D woven composites against such a material. In such studies, fatigue degradation is always accelerated by the $z$-binders $[91,127,128]$, even when the inplane stiffness and monotonic strength are increased or not changed significantly. Fig. 20 shows these trends using recently published $S-N$ curves for 3D woven composites with different $z$-binder contents and the $S-N$ curve for the equivalent $2 \mathrm{D}$ laminate under cyclic tension loading. Normalization of the fatigue strength $\left(\sigma_{\mathrm{f}}\right)$ against the monotonic strength $\left(\sigma_{0}\right)$ for each material shows that the rate of degradation of strength is accelerated by the z-binders, whereas the tabulated data show that the stiffness and monotonic strength are not affected strongly and can be either raised or lowered. For lives exceeding approximately 100 cycles, the fatigue life decreases with increasing $z$-binder volume content.

The fatigue properties of 3D woven composites under cyclic compression [87] and flexure [127] have been measured, but they have not been compared against an equivalent 2D laminate.

Stitched composites When the influence of stitching on the fatigue life of composites was originally examined by Mouritz and Cox [14] in the year 2000, virtually all fatigue data were for cyclic compression [70,71,97,129,131], with only a few available for cyclic tension [88,132]. In all cases, stitching reduced the compression and tension fatigue life of laminates; no study reported an improvement in fatigue performance. Data published since the original study also show that stitching reduces the fatigue life $[89,90,133]$, with only one case of stitching improving the fatigue performance [90]. This behavior contrasts with the static properties, where a significant percentage of materials show stiffness or strength increased by stitching. The reason for this difference is difficult to identify because an understanding of the influence of stitches on the fatigue mechanisms is lacking. Most studies did not study the initiation and development of fatigue damage in stitched laminates, but simply 
presented the fatigue life curves. Furthermore, the effects of the volume fraction and diameter of the stitches on the fatigue life curve and damage mechanisms have not been thoroughly investigated.

An outstanding issue with the fatigue behavior is predicting when the stitches will or will not change the fatigue mechanism. Due to the lack of information about the fatigue damage mechanisms and the laminate properties (e.g. fibre volume content, microstructural defects) in most studies, it is difficult to identify which stitching conditions and/or laminate properties result in a knock-down in fatigue strength without an apparent change to the fatigue mechanism (e.g. Fig. 18) and which stitching conditions change the fatigue process (e.g. Fig. 19). This lack of predictive capability is an impediment to the use of stitched composites in fatigue-loaded structures.

Pinned composites Fatigue data for pinned carbon-epoxy composites under cyclic tension [36], compression [58] and flexure [57] show that the fatigue strength is always reduced by pinning (e.g. Figs $18 \& 19$ ). Fatigue life is reduced with increasing pin content and pin diameter, which is the same behaviour observed for monotonic strength and modulus.

\section{Candidate Fatigue Mechanisms}

In addition to the fatigue mechanisms that occur in the equivalent $2 \mathrm{D}$ laminate, fatigue mechanisms in all classes of 3D composites are expected to arise at the microstructural defects associated with the $z$-binders. However, direct observations of fatigue mechanisms are limited and almost entirely post-mortem. X-ray computed tomography of progressive damage in the interior of specimens, especially in the few cubic mm spanned by a typical defect, combined with other damage monitoring techniques (e.g. acoustic emission), would be very revealing.

$3 D$ woven composites The dominant fatigue mechanism in $3 \mathrm{D}$ woven composites under cyclic compression loading, as in monotonic compression, is kink band formation. This occurs in aligned tows where they are crimped into misalignment near z-binders, as depicted in Fig. 5 [28,87]. For compression fatigue, Dadkhah et al. [87] proposed a fatigue law based on the gradual reduction of the ability of the matrix to 
support shear stress in misalignment defects. The critical local axial stress, $\sigma_{\mathrm{c}}$, for kink formation on any load cycle is:

$$
\sigma_{\mathrm{c}}=\frac{\tau_{\mathrm{c}}}{\phi}
$$

where $\tau_{\mathrm{c}}$ is the plastic shear yield stress of the matrix within the load-bearing fiber bundle and $\phi$ is the angle through which a tow segment is misaligned. Assume the law:

$$
\frac{d \tau_{\mathrm{c}}}{d N}=c_{1}(\Delta \tau)^{m} \approx c_{1}(\Delta \sigma \cdot \phi)^{m}
$$

where $N$ is the number of elapsed fatigue cycles, $c_{1}<0$ is a constant, and $\Delta \sigma$ and $\Delta \tau$ are the cyclic ranges of the local axial and shear stresses respectively. Assume also that failure follows the attainment of the condition that $\tau_{\mathrm{c}}$ falls below the peak local shear stress, $\left|\tau_{\max }\right|$, on any cycle. Then Eqs. (1) and (2) lead to a prediction for the number of cycles to failure [134]:

$$
N_{\mathrm{f}}=1+\frac{\tau_{0}-\left|\sigma_{\max }\right| \cdot \phi}{c_{1}(\Delta \sigma \cdot \phi)^{\mathrm{m}}}
$$

where $\left|\sigma_{\max }\right| \approx\left|\tau_{\max }\right| \phi$ is the magnitude of the maximum local compressive stress and $\tau_{0}$ is the pristine value of $\tau_{\mathrm{c}}$. When the defect associated with the misalignment $\phi$ refers to fibers that are nominally aligned with the load axis, then the local stress, $\sigma$, is approximately related to the applied stress, $\sigma_{\mathrm{a}}$, by $\sigma=\left(E_{1} / E\right) \sigma_{\mathrm{a}}$, where $E_{1}$ is the modulus of the local material and $E$ is that of the global composite. Therefore, Eq. (3) is similar in functional form to Basquin's law:

$$
N_{\mathrm{f}}=c_{2}\left(\Delta \sigma_{\mathrm{a}}\right)^{-\mathrm{m}}
$$

or, in the notation $S-N$ for stress and life,

$$
S=\sigma_{0}-m \log _{10} N
$$

Because $\sigma_{\max }$ is itself related to $\Delta \sigma$ and to the load ratio, $R$, Eq. (3) is not identical in form to Basquin's law; but for the common case that the exponent $m$ is much greater 
than unity, Eq. (3) and Basquin's law are very close and generate equally good fits to test data [134].

In Eq. (2), the factor $\Delta \sigma \cdot \phi$ is approximately the cyclic range of the axial shear stress (the shear stress component in an axis system that contains the local fiber direction) in a misaligned tow segment. Thus Eq. (2) describes shear weakening under the influence of unexpected axial shear stress in a nominally aligned tow. Where Eq. (2) does apply, the predicted fatigue life will obey the knockdown rule. The compressive $S-N$ data that fit straight lines are consistent with the hypothesis of material degradation implicit in Eq. (2). A change in the monotonic strength is attributed to a change in the misalignment angle, $\phi$, and when only $\phi$ is changed, the slope of a plot of $\log (\Delta \sigma)$ vs. $\log \left(N_{\mathrm{f}}\right)$, where $N_{\mathrm{f}}$ is given by Eq. (3), remains approximately equal to $m$.

A law similar to Eq. (2) may plausibly apply to tension fatigue as well as compression fatigue. The important fatigue mechanisms for 3D woven composites under cyclic tension include debonding of the $z$-binders from the surrounding composite and interior cracking of the z-binders [91,128]. However, a generalised fatigue law for 3D woven composites under cyclic tension has not been established due to the lack of sufficient $S-N$ data for different material systems.

Stitched Composites Under cyclic compression loading the reduction in fatigue strength of stitched composites is almost certainly caused by the fiber distortion around the stitches, which facilitates the formation of kink bands. Failure by kinking at the most heavily crimped fiber bundles in stitched composites is similar to the compressive fatigue mechanism described for 3D woven composites. Because kinking failure is the dominant fatigue mechanism for stitched and unstitched composites under cyclic compression loading, their $S-N$ curves are parallel and the only difference is the knock-down in monotonic strength [70,71,97,129-131].

Tension fatigue life curves of stitched composites can be parallel [90] or not parallel $[88,90,133]$ to that of the equivalent $2 \mathrm{D}$ laminate, with the latter case implying a change in fatigue mechanism caused by the stitches. Shah Khan and Mouritz [88] 
examined the tensile fatigue mechanisms of stitched composites which showed more rapid fatigue strength degradation than the unstitched material. Under cyclic tension loading, the stitches debonded from the surrounding material, which accelerated the fatigue damage rate in the stitched composites. The debonding was possibly caused by relatively weak bonding between the stitches (made of spun Kevlar) and the surrounding fibreglass material. High stress concentration at the stitch-laminate interface caused by the large mismatch in the transverse elastic modulus of the stitches (which is relatively low) and the in-plane stiffness of the fibreglass (which is much higher) may have contributed to the debonding. The formation of cracks at the stitches reduced the fatigue strength and fatigue life of the stitched composites. Obviously, stitch debonding does not occur in the equivalent 2D laminate. This difference in the tension fatigue mechanism is the likely reason for the fatigue life curves of the stitched and unstitched materials not being parallel.

Pinned laminates The fatigue mechanisms of pinned carbon-epoxy laminates have investigated for cyclic compression [58], tension [36,56] and bending [56,57]. As with 3D woven and stitched composites, the dominant fatigue mechanism under cyclic compression is kinking of crimped load-bearing fibres, which is also the failure mechanism under monotonic compression [35,58,103]. However, the slopes of the compression fatigue curves for the pinned and unpinned materials are not the same (Fig. 19). The steeper slope for the pinned composites implies that the pins accelerate the fatigue damage rate. The most likely mechanism is damage in regions around pins where fibers have been misaligned. Prior work on tape and textile polymer composites has put forward two possible mechanisms: the attrition of fibers where microfracture of the fiber-matrix interface has permitted relative sliding between the fibers and matrix [94]; and softening and damage of the resin itself under local cyclic shear, for which evidence has been most compelling in studies of compression fatigue [87,94]. Under cyclic compression loading, both of these mechanisms act where fibers are misaligned, i.e., where significant local shear stresses arise in coordinates that are aligned with the local fiber direction. Under cyclic compression loading, progressive shear softening of the matrix causes more rapid formation of kink bands, while progressive loss of fiber strength occurs under cyclic tension. However, no certain conclusions are possible about how variations in these mechanisms might account for the trends in fatigue effects (i.e., in the slope $m$ of the $S-N$ curves) with pin density. 
Nevertheless, the fact that fatigue effects are weak in the absence of pins and strong in their presence points very strongly to the presence of fatigue mechanisms in the misaligned fibers.

\section{CONCLUSIONS}

Through-thickness reinforcement of polymer laminates with woven tows, stitches or pins is an effective method of increasing delamination toughness and damage tolerance. A large body of research published over the past twenty years has shown that through-thickness reinforcement also changes the in-plane static and fatigue properties. Critical appraisal of property data reveals trends and differences between 3D woven, stitched and pinned materials which are not apparent when a single material is studied in isolation, which is often the case.

The in-plane static properties of composites can be increased by through-thickness reinforcement with woven $z$-binders or stitches, but never by pins. The increase to the mechanical properties of 3D woven and stitched composites above their equivalent $2 \mathrm{D}$ material is typically under $20 \%$, and is not or only weakly dependent on the volume content or diameter of the $z$-binders. The property increase is presumably caused by an increase in the in-plane fiber volume fraction due to compaction of the woven or stitched laminate preform by the $z$-binders. The compaction increases with the tautness of the woven $z$-binders or stitches during the through-thickness reinforcement process, but is not affected by their volume fraction or size. This would explain why the improvement in properties is not dependent on the amount or size of the $z$-binders. However, it is not possible to state conclusively that this is the cause because many researchers fail to report important data, including the in-plane fibre volume contents of the $3 \mathrm{D}$ and equivalent $2 \mathrm{D}$ materials, needed to interpret improvements in properties. Such property increases cannot be useful to design engineers until they are properly correlated with more accurate data for the fiber volume fraction and proven to be repeatable.

The stiffness and strength of 3D woven and stitched composites can be reduced by their $z$-binders. The reduction to the properties, which is usually under $20 \%$, does not correlate with the volume fraction or diameter of the $z$-binders. In contrast, the loss in stiffness and strength of pinned materials increases at an approximately linear rate 
with the pin content and pin size. The reduction to stiffness is attributed to geometric defects (fibre crimp and waviness) which induce local softening in the volume of material surrounding each $z$-binder. Reductions to the strength properties are also controlled by microstructural defects, such as clusters of broken and damaged fibres reducing tensile strength and crimped fibres lowering compressive strength. Quantitative analysis of defects in 3D composites, particularly woven and stitched materials, and direct observations of their influence on failure mechanisms under load is lacking. Until this information is available, theoretical predictions of the failure strength of 3D woven and stitched composites (including the influences of $z$-binder content and $z$-binder size) are not possible.

The observation that the stiffness and strength of 3D woven and stitched composites do not correlate strongly with their $z$-binder content implies that increasing the volume fraction of through-thickness reinforcement to promote high delamination toughness and damage tolerance will not necessarily result in a prohibitive reduction to the in-plane properties. With pinned laminates, however, their properties always decrease progressively with increasing pin content, and therefore a high enough concentration of pins to improve damage resistance may result in a potentially unacceptable loss to the in-plane properties.

The fatigue properties of 3D woven, stitched and pinned composites are always reduced by the $z$-binders (with the exception of one stitched material). The fatigue properties are reduced in two ways. In the first, the fatigue life curve for the $3 \mathrm{D}$ composite is reduced by the $z$-binders, although it remains parallel with the $S$ - $N$ curve for the equivalent 2D laminate. In this case the loss in fatigue performance in due solely to the knock-down in monotonic strength caused by microstructural defects, and the fatigue mechanism is presumably not changed by the $z$-binders. However, comparative studies of the initiation and growth of fatigue-induced damage in 2D and 3D composites with parallel $S-N$ curves have not been performed to confirm whether the fatigue process is always the same. In the second way, the fatigue life curves for the $2 \mathrm{D}$ and $3 \mathrm{D}$ materials are not parallel. This implies the $z$-binders are influencing the fatigue process and, in most cases, accelerating the loss in fatigue strength with increasing number of load cycles. Studies on 3D woven, stitched and pinned composites that show this trend reveal increased incidence of fatigue-induced damage 
at the $z$-binders, which accelerates the rate of degradation of fatigue strength. An outstanding issue is determining the conditions when $z$-binders in 3D woven, stitched and pinned materials will alter the fatigue process. It is not currently possible to predict conditions under which the $z$-binder have no influence on the fatigue process, and those conditions when the z-binders will accelerate or slow the rate of degradation. This issue can be resolved through detailed studies relating S-N curves to microstructural defects caused by the z-binders before fatigue loading and the initiation and growth of damage from z-binders under cyclic loading.

\section{Acknowledgments}

BNC was supported by the U.S. Army Research Office, contract DAAD19-99-C0042, administered by Dr. David Stepp.

\section{REFERENCES}

1. Tong L, Mouritz AP, Bannister MK. 3D Fibre Reinforced Polymer Composites, London: Elsevier, 2002.

2. Dransfield K, Baillie C, Mai Y-W. Improving the delamination resistance of CFRP by stitching - a review, Comp Sci \& Tech, 1994;50:305-317.

3. Partridge IK, Cartié DDR, Bonnington T. Manufacture and performance of z-pinned composites', In: Shonaike G, Advani S. editors. Advanced Polymeric Composites, CRC Press, FL, 2003.

4. Mouritz AP. Review of z-pinned composite laminates, Comp. 2007;38A:2383-2397.

5. Freitas G, Fusco T, Campbell T, Harris J, Rosenberg, S., Z-fiber technology and products for enhancing composite design, In: Proceeding of $83^{\text {rd }}$ Meeting of the AGARD SMP, Florence, Italy, 2-3 Nov 1996.

6. Frietas G, Magee C, Boyce J, Bott R. Service tough composite structures using Z-fiber process, Proceedings of the $9^{\text {th }}$ DoD/NASA/FAA Conference on Fibrous Composites, Lake Tahoe, Nevada, 1991.

7. Freitas G, Magee C, Dardzinski P, Fusco T. Fiber insertion process for improved damage tolerance in aircraft laminates, J. Adv. Mat., 1994:24:36-43.

8. Jain LK and Mai Y-W. On the effect of stitching on mode I delamination toughness of laminated composites. Comp Sci Tech. 1994:51:331-345

9. Jain LK and Mai Y-W. Determination of mode II delamination toughness of stitched laminated composites. Comp Sci Tech. 1995:55:241-253.

10. Cox BN. Simple, conservative criteria for buckling and delamination propagation in the presence of stitching, J. Comp. Mats, 2000;34:1136-47.

11. Cox BN, Massabò R, Kedward KT. Suppression of delaminations in curved structures by stitching, Comp. 1996:27A:1133-1138.

12. Mouritz AP, Bannister MK, Falzon PJ, Leong KH. Review of applications for advanced threedimensional fibre textile composites. Comp 1999; 30A:1445-1461.

13. Mouritz AP, Leong KH, Herszberg I. A review of the effect of stitching on the in-plane mechanical properties of fibre-reinforced polymer composites, Comp 1997; 28A:979-991.

14. Mouritz AP, Cox BN. A mechanistic approach to the properties of stitched laminates, Comp., 2000;31A:1-27.

15. Macander AB, Crane PM, Camponeschi ET, Fabrication and mechanical properties of multidimensionally (X-D) braided composite materials, In: Composite Materials: Testing \& Design, ASTM STP 893, Philadelphia,: American Society for Testing and Materials, 1986, pp. 422-443. 
16. Dell'Anno G, Cartié DD, Partridge IK, Rezai A. Exploring mechanical property balance in tufted carbon fabric/epoxy composites, Comp., 2007;38A: 2366-2373.

17. Cartié DDR, Dell' Anno G, Poulin E, Partridge IK. 3D reinforcement of stiffener-to-skin T-joints by z-pinning and tufting, Eng Frac Mech 2006;73:2532-2540.

18. Colin de Verdiere MC, Pickett AK, Skordos AA, Witzel V. Evaluation of the mechanical and damage behaviour of tufted non crimped fabric using full field measurements, Comp Sci Tech, 2009:69:131-138.

19. Ishikawa T. Overview of trends in advanced composite research and applications in Japan, Adv Comp Mat, 2006:15:3-37.

20. Kato T, Iwahori Y, Ishikawa T. Evaluation of materials properties of advanced composites zanchor laminates, In: Proceedings of $37^{\text {th }}$ International SAMPE Technical Conference, Seattle, USA, 2005.

21. Curiskis J, Durie A, Nicolaidis A, Herszberg I, Development in multiaxial weaving for advanced composite materials, In: Proceedings of $11^{\text {th }}$ International Conference on Composite Materials, July 14-18 1997, Gold Coast, pp. 87-96.

22. Dickinson L, Mohamed M, Bogdanovich A, 3D weaving: what, how, and where. In: Proceedings of SAMPE Conference, 23-27 May 1999, Long Beach CA.

23. Wittig J. Recent developments in the robotic stitching technology for textile structural composites. J. Text. App. Tech. Man., 2001;2: 1-8.

24. Lee B, Leong KH, Herszberg I. The effect of weaving on the tensile properties of carbon fibre tows and woven composites, J. Rein. Plas. Comp, 2001:20;652-670.

25. Lee L, Rudov-Clark S, Mouritz AP, Bannister MK, Herszberg I. Effect of weaving damage on the tensile properties of three-dimensional woven composites, Comp. Struct. 2002:57;405-413.

26. Mouritz AP, Lee L, Rudov-Clark S, Bannister MK. Fibre damage in the manufacture of advanced three-dimensional woven composites, Comp., 2003;34A:963-970.

27. Herszberg I, Weller T, Leong KH, BannisterMK. The residual tensile strength of stitched and unstitched carbon/epoxy laminates impacted under tensile load, In: Proceedings 1st Aust. Congress on Applied Mechanics, 21-23 Feb. 1996, pp. 309-314.

28. Cox BN, Dadhkak MS, Morris WL, Flintoff JG, Failure mechanisms of 3D woven composites in tension, compression and bending, Acta Met. et Mat., 1994;42:3967-3984.

29. Coman F, Herszberg I, Bannister M, John S. Design and analysis of 3D woven preforms for composite structures, Sci Eng Comp Mat, 1996:5:83-96.

30. Callus PJ, Mouritz AP, Bannister MK, Leong KH. Tensile properties and failure mechanisms of 3D woven GRP composites, Comp., 1999;30A:1277-1287.

31. Kuo W-S, Ko T-H. Compressive damage in 3-axis orthogonal fabric composites, Comp., 2000;31:1091-1105.

32. Desplentere F, Lomov SV, Woerdeman DL, Verpoest I, Wever M, Bogdanovich, Micro-CT characterization of variability in 3D textile architecture. Comp Sci Tech. 2005:65:1920-1930.

33. Reeder JR, Stitching vs a toughened matrix: compression strength effects, J Comp Mat. 1995;29:2464-2487.

34. Dickinson LC, Farley GL, Hinders MK. Prediction of effective three-dimensional elastic constants of translaminar reinforced composites, J. Comp. Mats. 1999:33;1002-1029.

35. Steeves CA, Fleck NA. In-plane properties of composite laminates with through-thickness pin reinforcement, Int. J. Solids Struct. 2006;43:3197-3212.

36. Chang P, Mouritz AP, Cox BN. Properties and failure mechanisms of z-pinned laminates in monotonic and cyclic tension, Comp, 2006;37A:1501-1513.

37. $\mathrm{Wu} \mathrm{E}$, Liau $\mathrm{J}$, Impact of unstitched and stitched laminates by line loading, $\mathrm{J}$ Comp Mat. 1994;28:1640-1658.

38. Farley, G.L., 1992, A mechanism responsible for reducing compression strength of through-thethickness reinforced composite material, J. Comp. Mat., 1992;26:1784-1795.

39. Leong KH, Lee B, Herszberg I, Bannister MK. The effect of binder path on the tensile properties and failure of multilayer woven CFRP composites. Comp. Sci. Tech 2000;60:149-156.

40. Mouritz AP. Flexural properties of stitched GRP laminates. Comp., 1996;27A:525-530.

41. Rossi GT. Evaluation of 3-D reinforcements in commingled, thermoplastic structural elements. In: Proceedings of the American Helicopter Society, 22-24 May 1989. pp 509-515.

42. Miao Y, Zhou E, Wang Y, Cheesman BA, Mechanics of textile composites: microgeometry. Comp Sci Tech, 2008:68:1671-1678.

43. Djukic L. Tow visualisation in woven composites using x-ray computed tomography. Recent Adv. Tex. Comp. 2008: 417-425. 
44. Schilling PJ, Bhanuprakash RK, Tatiparthi AK, Verges MA, Herrington PD. X-ray computed microtomography of internal damage in fiber reinforced polymer matrix composites, Comp Sci Tech, 2005:65:2071-2078.

45. Cox BN, Spearing SM, Mumm DR, Practical challenges in formulating virtual tests for structural composites, In: Mechanical Response of Composites, PP Camanho, CG Davla, ST Pinho (editors). Dordrecht: Springer Science and Business Media, 2008, pp. 57-75.

46. Moffat AJ, Wright P, Buffière Y-T, Sinclair I, Spearing SM. Micromechanisms of damage in $0^{\circ}$ splits in a $[90 / 0]_{\mathrm{S}}$ composite material using synchrotron radiation computed tomography. Scripta Mat., 2008;59:1043-1046.

47. Wright P, Fu X, Sinclair I, Spearing SM. Ultra high resolution computed tomography of damage in notched carbon fiber-epoxy composites. J. Comp. Mat., 2008;42:1993-2002.

48. Rugg KL, Cox BN. Deformation mechanisms of dry textile preforms under mixed compressive and shear loading, J. Rein. Plas. Comp. 2004:23:1425-1442.

49. Davis JG, Bohon H L, First NASA Advanced Composites Technology Conference, Seattle, Washington, 1990, NASA Conference Publication 3104.

50. Ding YQ, Wenger W, McIlhagger R., 1993, 'Structural characterization and mechanical properties of 3-D woven composites', In: Proceedings of European SAMPE Conference, 1993.

51. Arendts FJ, Drechler K, Brandt J. Advanced textile structural composites - status and outlook, In: Proceedings of the International Conference on Advanced Composite Materials, T. Chandra and A.K. Dhingra (editors), 1993, pp. 409-416.

52. Guess TR, Reedy ED. Comparison of interlocked fabric and laminated fabric Kevlar 49/epoxy composites, J. Comp. Tech. \& Res., 1985;7:136-142.

53. Rudov-Clark S, Mouritz AP, Bannister MK. Tensile fatigue properties of 3D woven composites, In: Proceedings of the $14^{\text {th }}$ International Conference on Composite Materials, 14-18 July 2003, San Diego, Paper 0816.

54. Gatehouse I., Mode I fracture toughness, tensile and permeability characterisation of 3D woven textile reinforced polymer composites, Master of Engineering, University of Auckland, 2007.

55. Partridge IK, Cartié DDR, Troulis M, Grassi M, Zhang X. Evaluating the mechanical effectiveness of z-pinning, In: Proceedings of the SAMPE Technical Conference, September 2004.

56. Chang $\mathrm{P}$. The mechanical properties and failure mechanisms of z-pinned composites, $\mathrm{PhD}$ Thesis, Royal Melbourne Institute of Technology, 2006.

57. Chang P, Mouritz AP, Cox BN. Flexural properties of z-pinned laminates, Comp., 2007;38A:224251.

58. Mouritz AP. Compression properties of z-pinned composite laminates, Comp. Sci. Tech. 2007;67:3110-3120.

59. Thuis HGSJ, Bron E. The effect of stitching density and laminate lay-up on the mechanical properties of stitched carbon fabrics, National Lucht-en Ruimtevaartlaboratorium, Report NLR CR 96126L, 1996.

60. Harris H, Schinske N, Kruger R, Swanson B. Multiaxial stitched preform reinforcement, In: Proceedings of the $6^{\text {th }}$ Annual ASM.ESD Advanced Composites Conference, 8-11 October 1991, pp. 433-434.

61. Jain LK, Mai Y-W. Recent work on stitching of laminated composites - theoretical analysis and experiments, In: Proceedings of the $11^{\text {th }}$ International Conference on Composite Materials, 14-18 July 1997, pp. I-25-I-51.

62. Dexter HB, Funk JG Impact resistance and interlaminar fracture toughness of through-thethickness reinforced graphite/epoxy, AIAA paper 86-CP, 1996, pp. 700-709.

63. Pang F, Wang $\mathrm{CH}$, Bathgate RG. Creep response of woven fibre composites and the effect of stitching, Comp. Sci. Tech., 1997;57:91-98.

64. Larsson F. Damage tolerance of a stitched carbon/epoxy laminate, Comp. 1997;28A:923-934.

65. Wu E, Wang J. Behaviour of stitched laminates under in-plane tensile and transverse impact loading, J. Comp. Mat., 1995;29:2254-2279.

66. Kang TJ, Lee SH. Effect of stitching on the mechanical and impact properties of woven laminate composite, J. Comp. Mat. 1994:28:1574-1587.

67. Stringer LG, Hiley MJ. Through-thickness reinforcement of composites: z-pinning, stitching and 3-D weaving, In: Proceedings of the $14^{\text {th }}$ International Conference on Composite Materials, 14-18 July 2003, San Diego, Paper No. 1312.

68. Guess TR, Reedy ED. Additional comparisons of interlocked fabric and laminated fabric Kevlar 49/epoxy composites, J. Comp. Tech. \& Res, 1986;8:163-168.

69. Hamilton S, Schinske N, Multiaxial stitched preform reinforcements, In Proc. $6^{\text {th }}$ Annual ASM/ESD Adv. Comp. Conf., 8-11 Oct 1990, pp. 433-434. 
70. Vandermey NE, Morris DH, Masters JE. Damage development under compression-compression fatigue loading in stitched uniwoven graphite/epoxy composite material, NASA Report PB91236026, 1991.

71. Furrow, KW, Loos AC, Cano RJ. Environmental effects on stitched RTM textile composites, J. Rein. Plas. Comp., 1996;15:378-419.

72. Mouritz AP, Chang P, Kong H, Cox BN. Tensile properties of z-pinned polymer composites, In: Proceedings of the $27^{\text {th }}$ International SAMPE Europe Conference, 27-29 March 2006, Paris, pp. 371-376.

73. Roth YC, Himmel N. Theoretical model and experimental investigation on the effect of stitching on the in-plane stiffness of CFRP, In: Proceedings of the 10th European Conference on Composite Materials, Brugge, Belgium, 3 to 7 June 2002.

74. Cox BN, Carter WL, Fleck NA, A binary model of textile composites - I. Formulation, Acta Met. et Mat., 1994;42:3463-3479.

75. Cox BN, Dadkhah MS, The macroscopic elasticity of 3D woven composites, J. Comp. Mater. 1995;29:785-819.

76. Xu J, Cox BN, McGlockton MA, Carter WC, 1995, A binary model for textile composites - II. the elastic regime, Acta Met. et Mat.,1995;43:3511-3524.

77. Rudov-Clark S, Lomov SV, Bannister MK, Mouritz AP, Verpoest, I. Geometric and mechanical modeling of 3D woven composites, In: Proceedings of the $14^{\text {th }}$ International Conference on Composite Materials, 14-18 July 2003, San Diego, Paper 0817.

78. Gunnion AJ, Scott ML, Thomson RS, Hachenberg D. Thickness effects on the compressive stiffness and strength of stitched composite laminates, Comp. Struct., 2004;66:479-486.

79. Kim SJ, Lee CS, Shin H, Tong L. Anisotropic material characterisation of 3D orthogonal woven composite structures, In: Proceeding of the American Institute of Aeronautics \& Astronautics, 2001, Paper No. 570.

80. Tan P, Tong L, Steven GP. Modelling approaches for 3D orthogonal woven composites, J. Rein. Plas. \& Comp., 1998;17:545-577.

81. Tan P, Tong L, Steven GP. Models for predicting thermomechanical properties of 3D orthogonal woven composites, J. Rein. Plas. \& Comp., 1999;18:151-185.

82. Tan P, Tong L, Steven GP. Micro-mechanics models for mechanical and thermo-mechanical properties of 3D angle interlock woven composites', Comp., 1999;30A:637-648.

83. Tan P, Tong L, Steven GP. Behaviour of 3D orthogonal woven CFRP composites. I: Experimental investigations', Comp., 2000;31A:259-271.

84. Tan P, Tong L, Steven GP. Behaviour of 3D orthogonal woven CFRP composites. II: Theoretical analysis and FEA modelling, Comp., 2000;31A:273-281.

85. Grassi M, Zhang X, Meo M. Prediction of stiffness and stresses in z-fibre reinforced composite laminates, Comp. 2002;33:1653-1664.

86. Grassi M. Numerical modelling of composite laminates with through-thickness-reinforcements. PhD Thesis, Cranfield University, 2000.

87. Dadkhah MS, Morris WL, Cox BN. Compression-compression fatigue in 3D woven composites, Acta Met. et Mat., 1995:43:4235-4245.

88. Shah Khan MZ, Mouritz AP. Fatigue behaviour of stitched GRP laminates, Comp. Sci. \& Tech., 1996;56:695-701.

89. Aymerich F, Priolo P, Sanna R, Sun CT. Fatigue behaviour of stitched composite laminates, In: Proceedings of the $13^{\text {th }}$ International Conference on Composite Materials, 25-29 June 2001, Beijing, Paper No. 1461.

90. Aymerich F, Priolo P, Sun CT. Static and fatigue behaviour of stitched graphite/epoxy composite laminates, Comp. Sci. \& Tech., 2003;63:907-917.

91. Rudov-Clark S, Mouritz AP. Tensile fatigue properties of a 3D orthogonal woven composite, Comp., 2008;39:1018-1024.

92. Arendts FJ, Drechsler K, Brandt J. The application of three-dimensional reinforced fiber-preforms to improve the properties of composites, In: Proceedings of the 34th International SAMPE Symposium, 8-11 May 1989, pp. 2118-2129.

93. Du X, Xue F, Gu Z. Experimental study of the effect of stitching on strength of a composite laminate, In: Proceedings of the International Symposium on Composite Materials \& Structures, 10-13 June 1986, pp. 912-918.

94. Piggott MR, Lam PWK. Fatigue failure process in aligned carbon-epoxies, In: ASTM-STP 1110. ASTM, Philadelphia. 1991, pp. 686-695.

95. Farley, G.L., B.L. Smith and J. Maiden, Compression response of thick layer composite laminates with through-the-thickness reinforcement, J. Rein. Plastics Comp., 1992;11, 787-810. 
96. Farley GL, Dickinson LC. Removal of surface loop from stitched composites can improve compression and compression-after-impact strengths, J. Rein. Plast. Comp., 1992;11:633-642.

97. Dow MB, Smith DL. Damage-tolerant composite materials produced by stitching carbon fabrics, In: Proceedings of the 21st International SAMPE Technical Conference, 25-28 Sept. 1989, pp. 595-605.

98. Hirokawa T, Yasuda J, Iwasaki Y, Nogucki Y. The characteristics of 3-D orthogonal woven fabric reinforced composites, In: Proceedings of the 36th International SAMPE Symposium, , Covina, CA: 1991, pp. 151-151.

99. Leong KH, Herszberg I, Bannister MK An investigation of fracture mechanisms of carbon epoxy laminates subjected to impact and compression-after-impact loading, Int. J. Crash, 1996;1:285294.

100. Herszberg I, Bannister MK Compression and compression-after-impact properties of thin stitched carbon/epoxy composites, In: Proceedings of the $5^{\text {th }}$ Australian Aerospace Conference, 20-23 March 1993, Melbourne.

101. Herszberg I, Leong KH, Bannister MK The effect of stitching on the impact damage resistance and tolerance of uniweave carbon/epoxy laminates, In: Proceedings of the $4^{\text {th }}$ International Conference Automated Composites, 6-7 Sept 1995, pp. 53-60.

102. Caneva C, Olivieri S, Santulli C, Bonifazi G. Impact damage evaluation on advanced stitched composites by means of acoustic emission and image analysis, Comp. Struct., 1993:25:121-128.

103. O'Brien TK, Krueger R. Influence of compression and shear on the strength of composite laminates with z-pinned reinforcement. Appl Comp. Mat. 2006;13:173-189.

104. Budiansky B, Fleck NA. Compressive failure of fibre composites, J. Mech. Phys. Solids, 1993;41:183-211.

105. Cox BN, Spearing SM, Mumm DR, Practical challenges in formulating virtual tests for structural composites, in Mechanical Response of Composites, PP Camanho, et al. (editors) Dordrecht: Springer Science and Business Media: 2008, pp. 57-75.

106. Wright P, Fu X, Sincalir I, Spearing SM. Ultra high resolution computed tomography of damage in notched carbon fiber-epoxy composites. J. Comp. Mat. 2008;42:1993-2002.

107. Cox BN, Dadkhah MS, Inman RV, Morris WL, Zupon J. Mechanisms of compressive failure in 3D composites, Acta Met. et Mat., 1992;40:3285-3298.

108. Kuo W-S, Ko T-H. Compressive damage in 3-axis orthogonal fabric composites. Comp. 2000;31A:1091-1105.

109. Cholakara MT, Jang BZ, Wang CZ. Deformation and failure mechanisms in 3D composites, In: Proceedings of the 34th International SAMPE Symposium, 8-11 May 1989, pp. 2153-2160.

110. Mouritz AP, Gallagher J, Goodwin AA. Flexural and interlaminar shear properties of stitched GRP laminates following repeated impacts, Comp. Sci. \& Tech., 1996;57:509-522.

111. Mouritz AP, unpublished data.

112. Cholakara MT, Jang BZ, Wang CZ. Deformation and failure mechanisms in 3D composites. In: Proceedings of the $34^{\text {th }}$ International SAMPE Symposium, 8-11 May 1989, pp. 2153-2160.

113. Massabò R, Cox BN. Concepts for bridged mode II delamination cracks,” J. Mech. Phys. Solids, 1999; 47:1265-1300.

114. Massabò R, Cox BN. Unusual characteristics of mixed mode delamination fracture in the presence of large scale bridging," Mech. Comp. Mater. \& Struct., 2001;8:61-80.

115. Rugg KL, Cox BN, Massabò R, Mixed mode delamination of polymer composite laminates reinforced through the thickness by z-fibers," Comp., 2002:33A:177-190.

116. Turrettini A. An investigation of the mode I and mode II stitch bridging laws in stitched polymer composites, Masters Thesis, University of California, Santa Barbara, 1996.

117. Cox BN, Massabò R, Mumm D, Turrettini A, Kedward K. Delamination fracture in the presence of through-thickness reinforcement, In Proceedings of the. 11th International Conference on Composite Materials, 14-18 July 1997, ed. M. L. Scott pp.I-159 to I-177.

118. Cartié DDR, Cox BN, Fleck BN. Mechanisms of crack bridging by composite and metallic rods, Comp., 2004;35A:1325-1336.

119. Cox BN, Sridhar N. A traction law for inclined fibre tows bridging mixed mode cracks, Mech. Comp. Mater. \& Struct., 2002:9:299-331.

120. Cox BN. Snubbing effects in the pullout of a fibrous rod from a laminate, Mech. Adv. Mat.\& Struct., 2005;12:85-98.

121. Cox BN. Constitutive model for a fiber tow bridging a delaminated crack. Mech. Comp. Mat. \& Struct., 1999;6:117-138.

122. Rugg K, Cox BN, Ward K, Sherrick GO. Damage mechanisms for angled through-thickness rod reinforcement in carbon-epoxy laminates, Comp. 1998;29A:1603-1613. 
123. Liu CH, Byan J, Chou T-W. Mode II interlaminar fracture toughness of three-dimensional textile structural composites. In: Proceedings of the $4^{\text {th }}$ Japan-US Conference on Composite Materials, Lancaster PA: Technomic Publishing, 1989, pp. 981-990.

124. Jain LK, Dransfield KA, Mai Y-W. On the effects of stitching in CFRPs-II. Mode II delamination toughness. Comp. Sci. \& Tech., 1998;58:829-837.

125. Mouritz AP, Jain LK. Further validation of the Jain and Mai models for interlaminar fracture of stitched composites. Comp. Sci. \& Tech., 1999;59:1653-1662.

126. Yan W. Lin H-Y, Mai YW. Mode II delamination toughness of z-pinned laminates, Comp. Sci \& Tech. 2004:64;1937-1945.

127. Ding YQ, Yan Y, McIlhagger R, Brown D. 'Comparison of the fatigue behaviour of 2-D and 3-D woven fabric reinforced composites', J. Mat. Proc.g Tech., 1995;55:171-177.

128. Mouritz AP. Tensile fatigue properties of 3D composites with through-thickness reinforcement, Comp. Sci. \& Tech., 2008;68:2503-2510.

129. Portanova MA, Poe CC, Whitcomb JD. Open hole and postimpact compressive fatigue of stitched and unstitched carbon-epoxy composites, In: Composite Materials: Testing and Design (Tenth Volume), ASTM STP 1120, ed. G.C. Glenn, American Society for Testing and Materials, Philadelphia, 1992, pp. 37-53.

130. Sun CT, Mignery LA, Jih CJ. A study of stitching as a through-thickness reinforcement in graphite/epoxy laminates, School of Aeronautics and Astronautics, Purdue University, Report CML 84-10, 1984.

131. Lubowinski SJ, Poe CC. Fatigue characterization of stitched carbon/epoxy composites, In: Proceedings of Fiber-Tex 1987 Conference, 1987, pp. 253-271.

132. Herszberg I, Loh A, Bannister MK, Thuis HGSJ. Open hole fatigue of stitched and unstitched carbon/epoxy laminates, In: Proceedings of the $11^{\text {th }}$ International Conference on Composite Materials, 14-18 July 1997, Gold Coast, Australia, pp. V-138 - V-148.

133. Mouritz AP. Fracture and tensile fatigue properties of stitched fibreglass composites, Proc Ins. Mech. Eng. Part L: Mats: Design \& App., 2004;218:87-93.

134. Piggott MR, Lam PWK. Fatigue failure processes in aligned carbon-epoxies. In: Proceedings of the 3th Symposium on Composite Materials: Fatigue and Fracture. 1991. Lake Buena Vista, Florida: American Society for Testing and Materials. 


\section{Figure Captions}

Figure 1. Fiber architectures for (a) 3D orthogonal interlock woven composites (schematic courtesy 3Tex Inc., Cary, North Carolina) (b) 3D angle interlock woven composites, (c) stitched quasi-isotropic composite and (d) pinned composite.

Figure 2. Fracture of in-plane fibres due to $z$-binder reinforcement. The fibers were broken by a sewing needle and stitch thread forced through a fibrous perform.

Figure 3. Distortion of in-plane fibres around a pin in a pinned composite (viewed normal to the laminate plane). Resin-rich regions occur where the fibres have been displaced by the pins.

Figure 4. Crimping of in-plane fibers (indicated by the arrows) at a $z$-binder within a pinned composite (viewed parallel to the laminate plane). From Chang et al. [36].

Figure 5. Schematic of crimping of an in-plane tow by a tensioned $z$-binder in an angle interlock weave. From Cox et al. [28].

Figure 6. Effect of pin content on the percentage reduction to the average fiber volume fraction of a unidirectional carbon-epoxy composite. The preform was either constrained or not constrained during the pinning process.

Figure 7. (a) Crimp of $z$-binders in an angle interlock weave, caused by throughthickness compaction during processing. (b) Misalignment of pins in a composite caused by loss of verticality during insertion and rotation during consolidation. (c) 1.8 $\mu \mathrm{m}$-resolution X-ray $\mathrm{CT}$ image of an internal volume of an angle interlock ceramic $\mathrm{SiC}-\mathrm{SiC}$ woven composite. Material distribution on three orthogonal planes (orange outlines) reveal fiber tows around a transpiration hole (formed using fugitive tows during matrix processing). The complexity of variances in 3D fiber deployment and matrix defects is evident (Barth, Cox, MacDowell, and Marshall, unpublished work, 2009).

Figure 8. Shear deformation of a tow, with local strains of order of magnitude unity, in a triaxial braid. Viewed through transparent platens that have subjected the braid to simultaneous through-thickness compression (into the plane of the figure) and through-thickness shear. Crossovers are locked up (no mutual rotation of tows). Tow segments deform by shear marked by splitting or sliding displacement concentrations (arrows).

Figure 9. Effect of $z$-binder content on the normalized tensile modulus of (a) 3D woven (b) stitched and (c) pinned composites. The plots for the stitched composites define the denier and material used for stitching. For example, $720 \mathrm{~d}$ Kevlar means the composite was stitched with 720 denier Kevlar yarn.

Figure 10. Effect of $z$-binder content on the normalized compression modulus of (a) stitched and (b) pinned composites. 
Figure 11. Effect of $z$-binder content on the normalized flexural modulus of (a) 3D woven (b) stitched and (c) pinned composites.

Figure 12. Effect of stitch diameter on the normalized modulus for a fixed stitch content $\left(0.01\right.$ stitches $\left./ \mathrm{mm}^{2}\right)$.

Figure 13. Effect of $z$-binder content on the normalized tensile strength of (a) 3D woven composites, (b) stitched composites and (c) pinned composites.

Figure 14. Effect of $z$-binder content on the normalized compression strength of (a)

3D woven \& z-pinned composites and (b) stitched composites.

Figure 15. Effect of $z$-binder content on the normalized flexural strength of (a) stitched and (b) pinned composites.

Figure 16. Effect of $z$-binder content on the normalized interlaminar shear strength of (a) 3D woven, (b) stitched and (b) pinned composites.

Figure 17. Measured traction vs. displacement relations for (a) a single stitch [116,117] and (b) a single fibrous pin [116] in a pre-cracked laminate under applied shear displacement. The stress is defined as the shear load divided by the normal cross-sectional area of the $z$-binder. The displacement is the total sliding displacement across a mid-laminar pre-crack. In these tests, both the stitches and pins were approximately normally oriented (pin angle $\phi$ as shown).

Figure 18. S-N curves for (a) stitched and (b) pinned carbon-epoxy composite and their equivalent 2D laminate which show parallel curves. The stitched materials were fatigued under cyclic tension [90] and the pinned materials under cyclic bending [57].Normalized S-N curves for the (c) stitched and (d) pinned materials in (a) and (b), respectively. The fatigue strength $\left(\sigma_{\mathrm{f}}\right)$ of the stitched and pinned materials is normalized against their monotonic strength $\left(\sigma_{0}\right)$ of their $2 \mathrm{D}$ laminate.

Figure 19. S-N curves for (a) stitched and (b) pinned carbon-epoxy composite and their equivalent 2D laminate which do not show parallel trends. The stitched [90] and pinned [36] materials were fatigued under cyclic tension. Normalized S-N curves for the (c) stitched and (d) pinned materials in (a) and (b), respectively. The fatigue strength $\left(\sigma_{\mathrm{f}}\right)$ of the stitched and pinned materials is normalized against their monotonic strength $\left(\sigma_{\mathrm{o}}\right)$ of their 2D laminate.

Figure 20. Effect of $z$-binder content on the tension fatigue life of 3D woven composites [91]. The fatigue stress $\left(\sigma_{\mathrm{f}}\right)$ is normalized against the monotonic strength $\left(\sigma_{\mathrm{o}}\right)$ for each material. The normalized tensile modulus $\left(\mathrm{E} / \mathrm{E}_{\mathrm{o}}\right)_{\mathrm{T}}$ and tensile strength $\left(\sigma / \sigma_{\mathrm{o}}\right)_{\mathrm{T}}$ are also given in the table inset. 


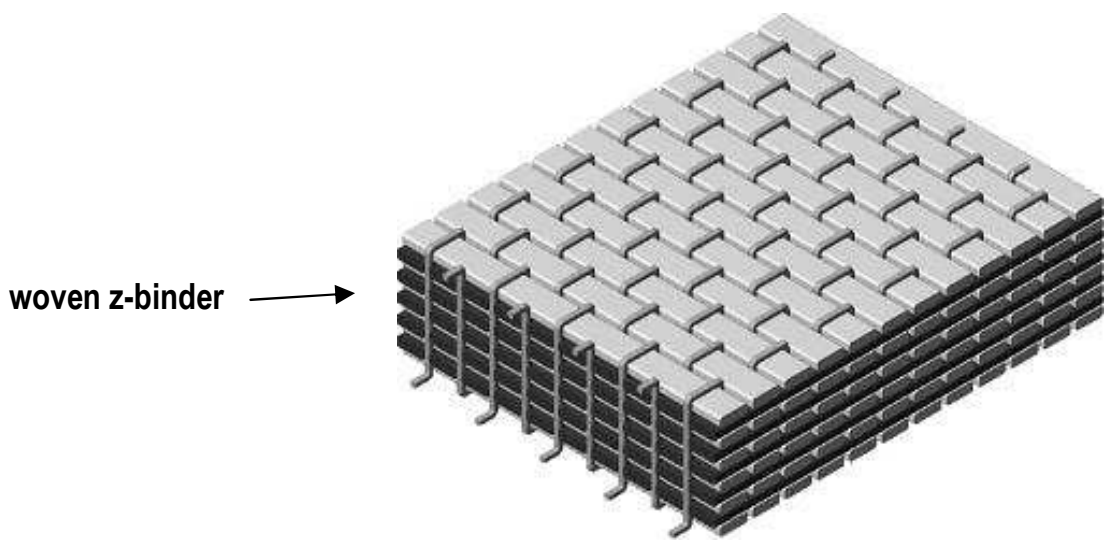

(a)

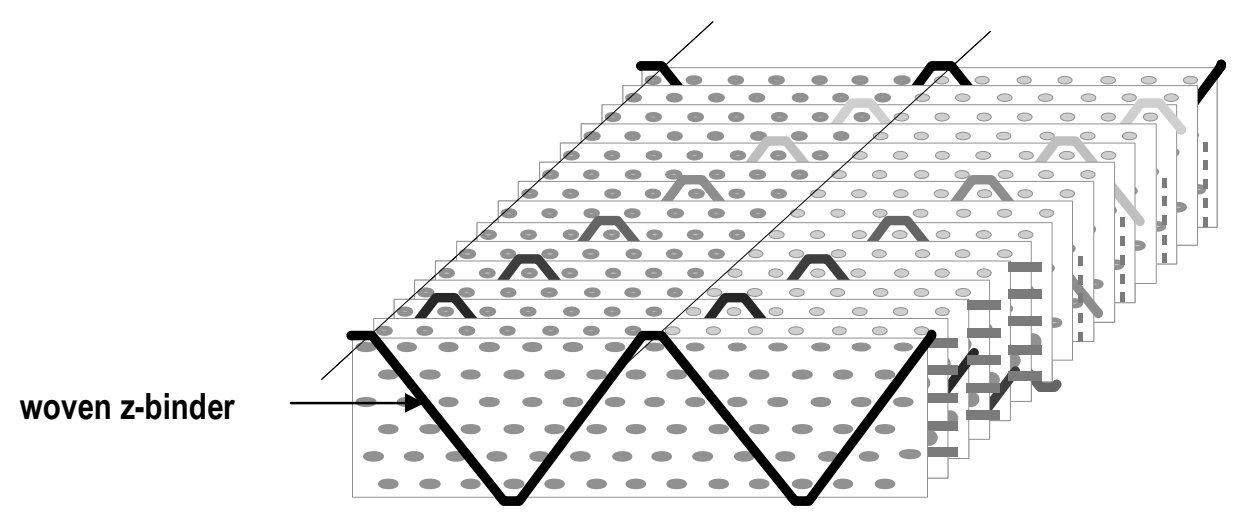

(b)

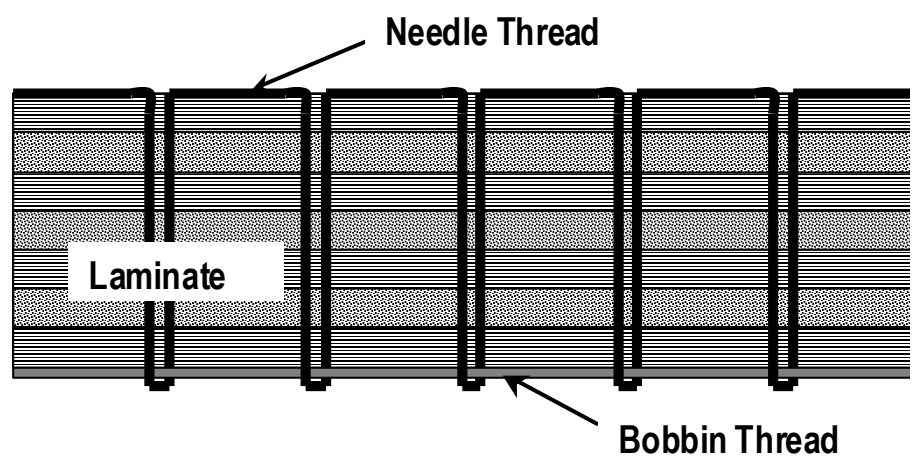

(c) 


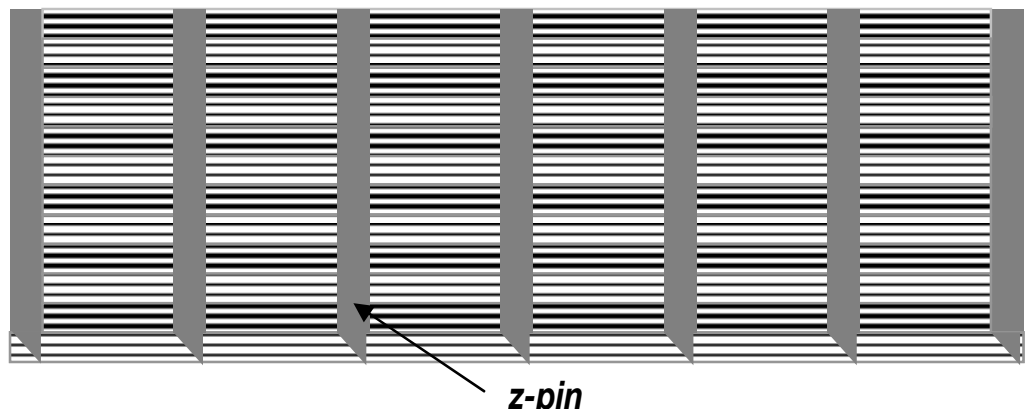

(d)

Figure 1. Fiber architectures for (a) 3D orthogonal interlock woven composites (schematic courtesy 3Tex Inc., Cary, North Carolina) (b) 3D angle interlock woven composites, (c) stitched quasi-isotropic composite and (d) pinned composite. 


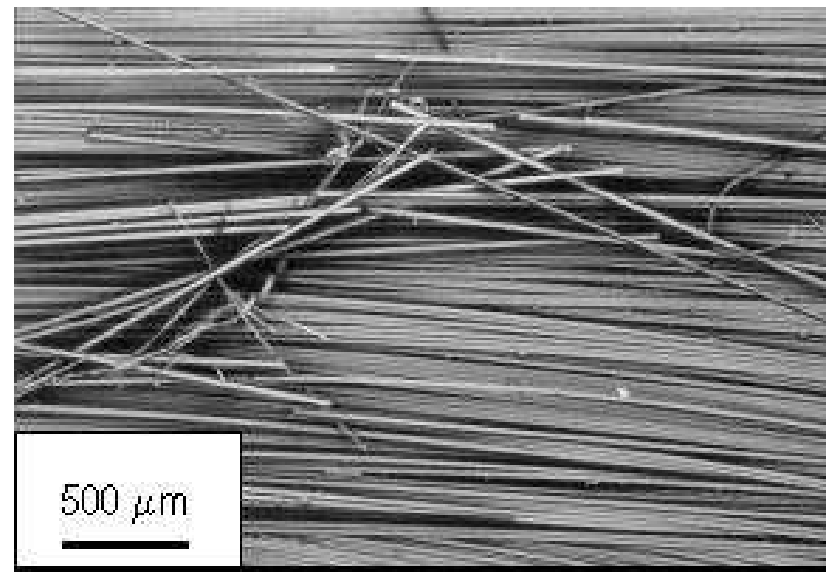

Figure 2. Fracture of in-plane fibres due to $z$-binder reinforcement. The fibers were broken by a sewing needle and stitch thread forced through a fibrous perform.

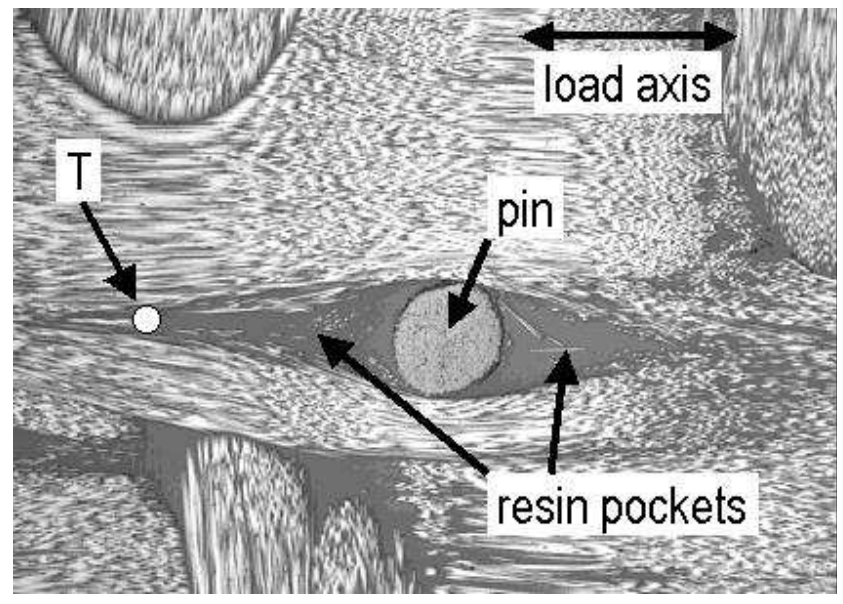

Figure 3. Distortion of in-plane fibres around a pin in a pinned composite (viewed normal to the laminate plane). Resin-rich regions occur where the fibres have been displaced by the pins. 


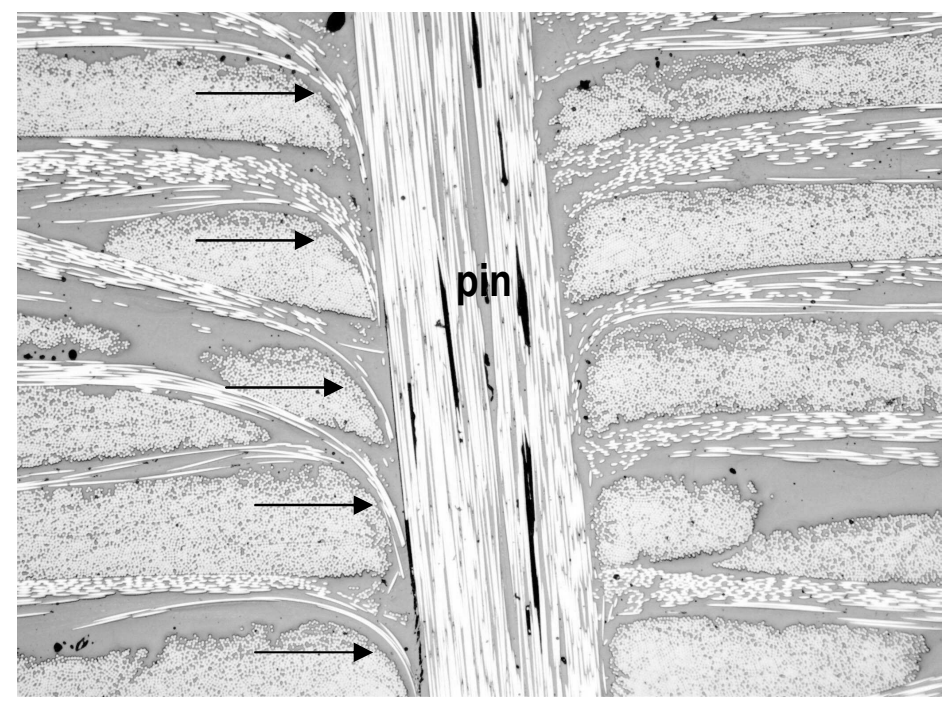

Figure 4. Crimping of in-plane fibers (indicated by the arrows) at a $z$-binder within a pinned composite (viewed parallel to the laminate plane). From Chang et al. [36].

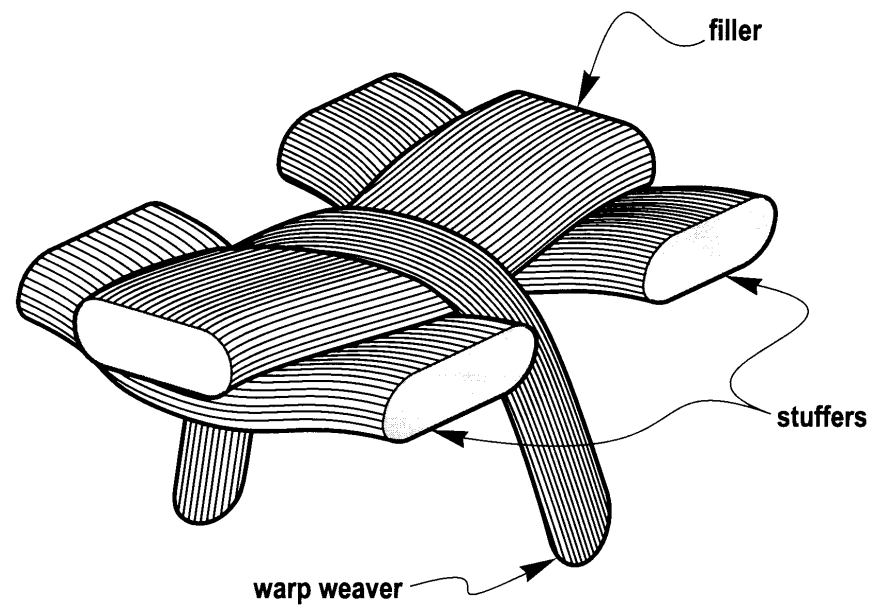

Figure 5. Schematic of crimping of an in-plane tow by a tensioned $z$-binder in an angle interlock weave. From Cox et al. [28]. 


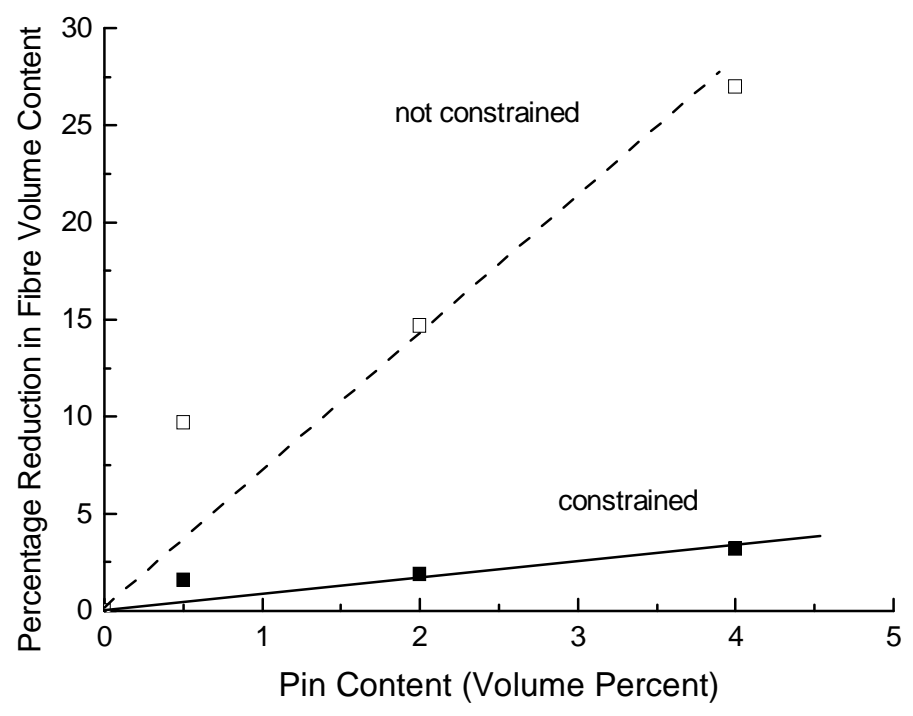

Figure 6. Effect of pin content on the percentage reduction to the average fiber volume fraction of a unidirectional carbon-epoxy composite. The preform was either constrained or not constrained during the pinning process. 


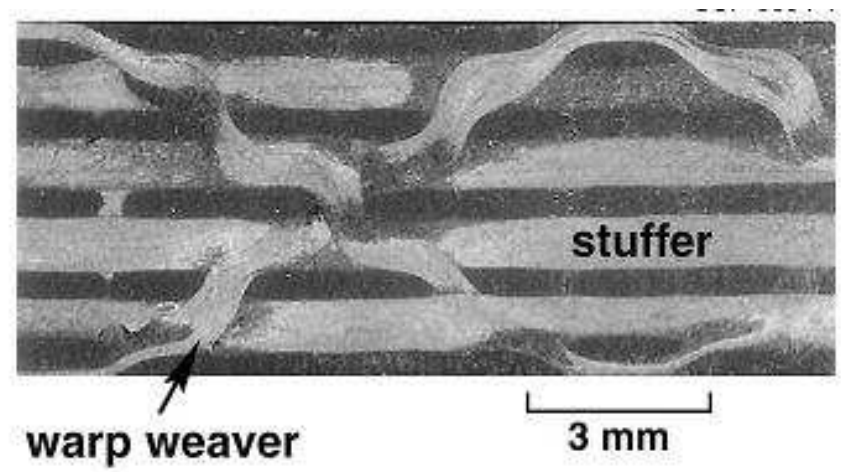

(a)

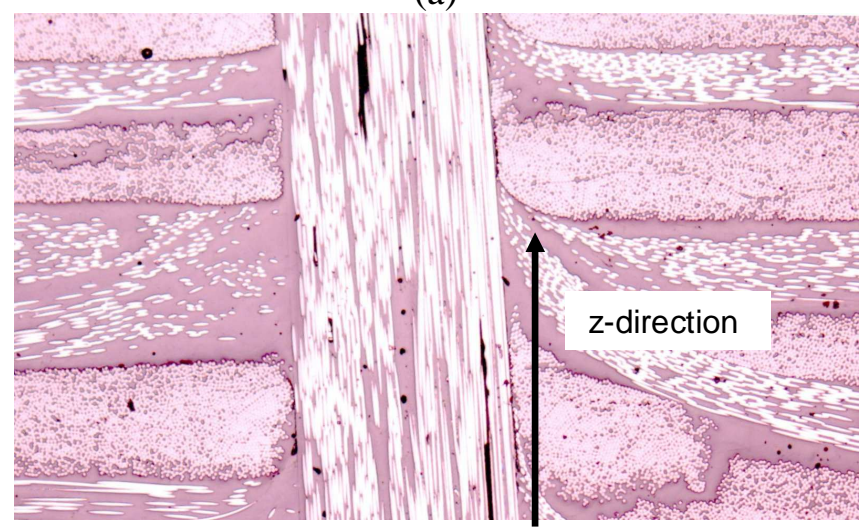

(b)

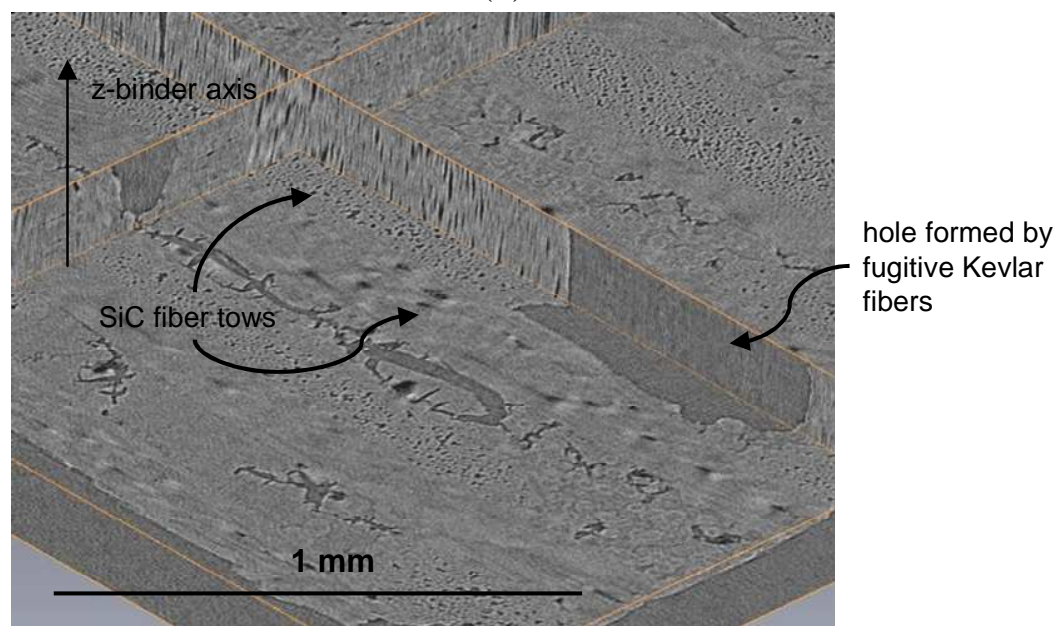

(c)

Figure 7. (a) Crimp of $z$-binders in an angle interlock weave, caused by through-thickness compaction during processing. (b) Misalignment of pins in a composite caused by loss of verticality during insertion and rotation during consolidation. (c) $1.8 \mu \mathrm{m}$-resolution X-ray CT image of an internal volume of an angle interlock ceramic SiC-SiC woven composite. Material distribution on three orthogonal planes (orange outlines) reveal fiber tows around a transpiration hole (formed using fugitive tows during matrix processing). The complexity of variances in 3D fiber deployment and matrix defects is evident (Barth, Cox, MacDowell, and Marshall, unpublished work, 2009). 


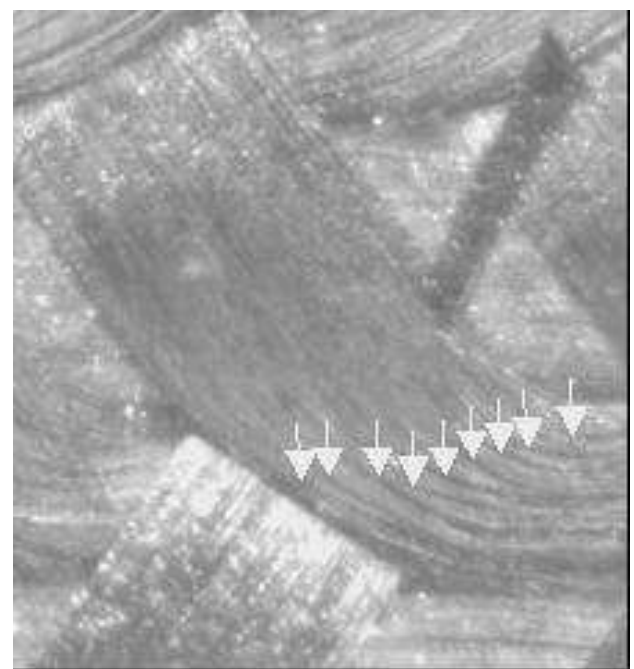

Figure 8. Shear deformation of a tow, with local strains of order of magnitude unity, in a triaxial braid. Viewed through transparent platens that have subjected the braid to simultaneous through-thickness compression (into the plane of the figure) and through-thickness shear. Crossovers are locked up (no mutual rotation of tows). Tow segments deform by shear marked by splitting or sliding displacement concentrations (arrows). 
Figure 9. Effect of z-binder content on the normalised tensile modulus of (a) 3D woven (b) stitched and (c) pinned composites. The plots for the stitched composites define the denier and material used for stitching. For example, $720 \mathrm{~d}$ Kevlar means the composite was stitched with 720 denier Kevlar yarn.

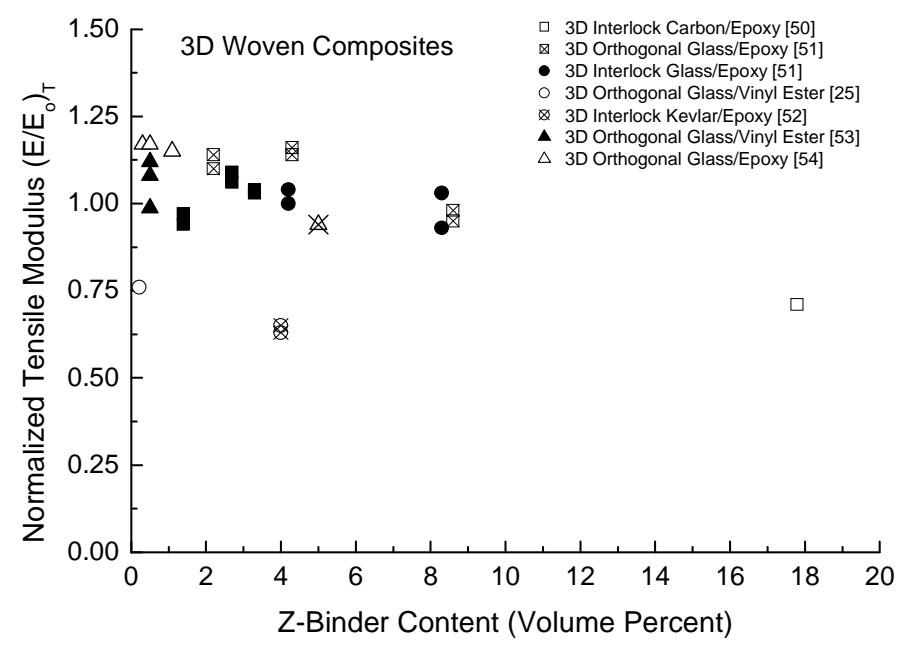

(a)

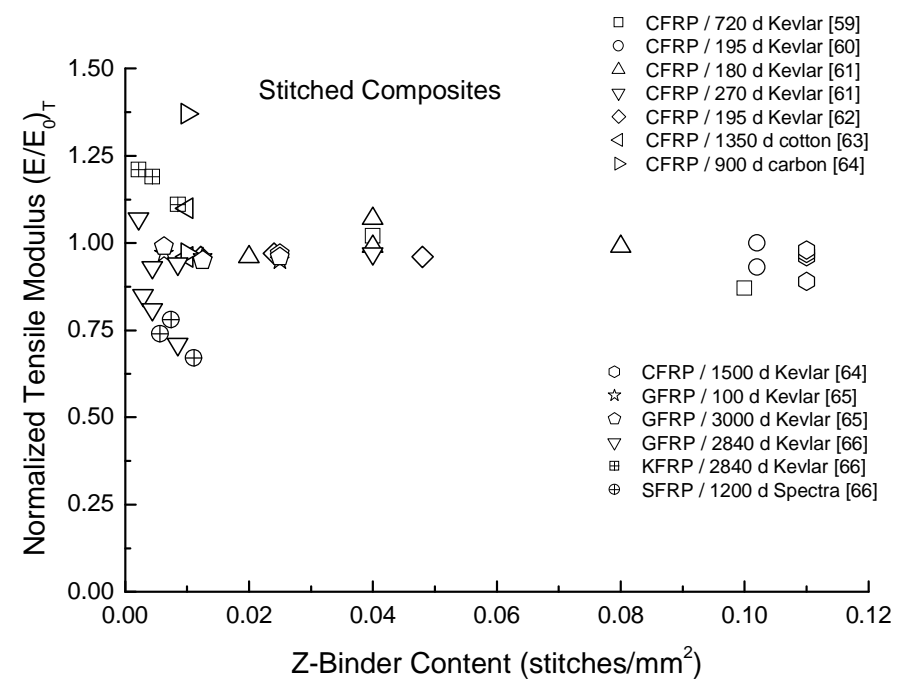

(b) 


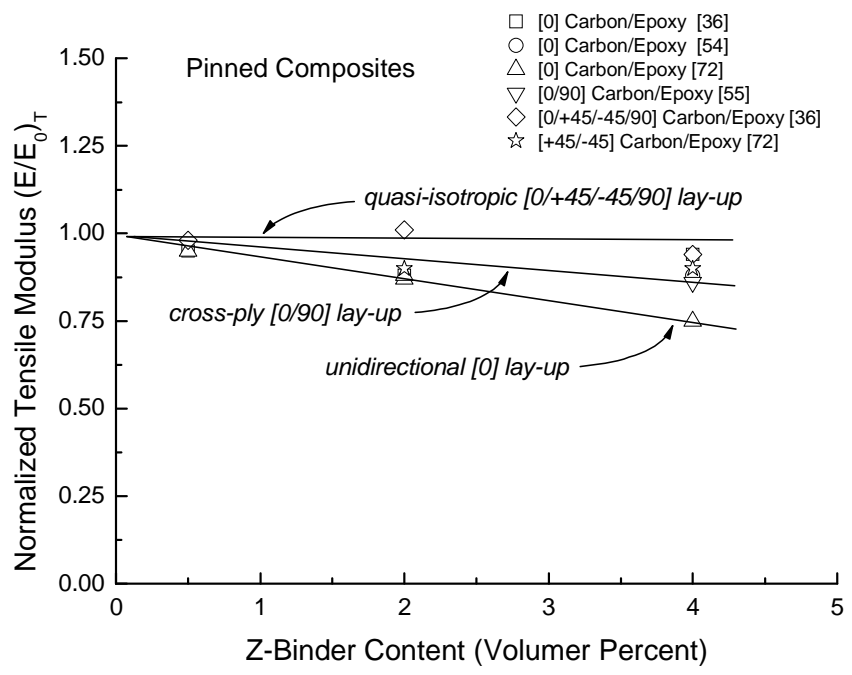

(c) 
Figure 10. Effect of z-binder content on the normalised compresive modulus of (a) stitched and (b) pinned composites. There is insufficient data to generate a plot for 3D woven composites.

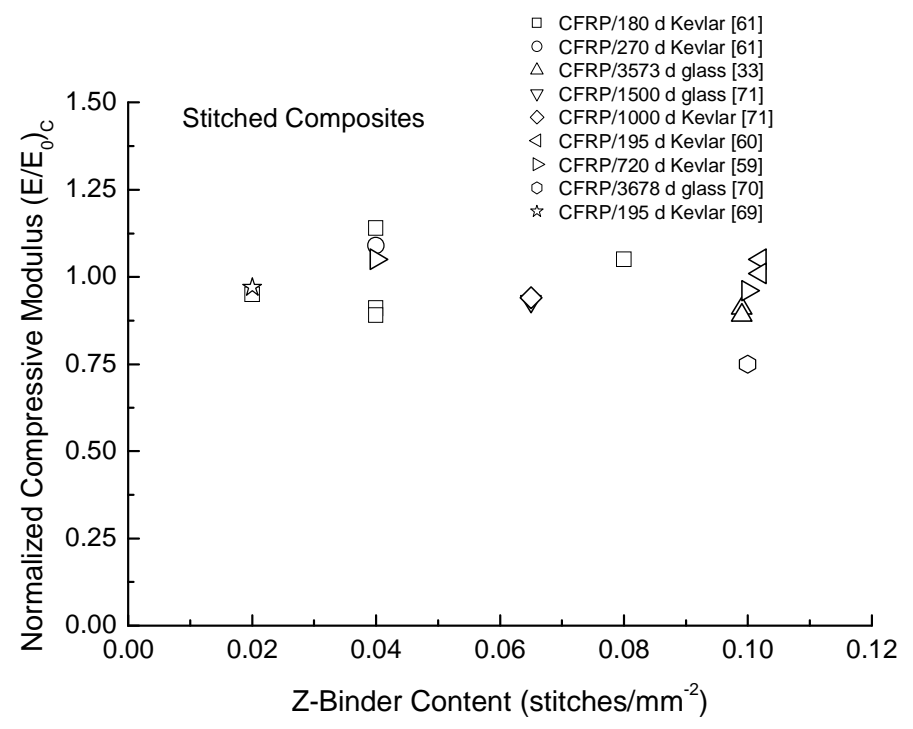

(a)

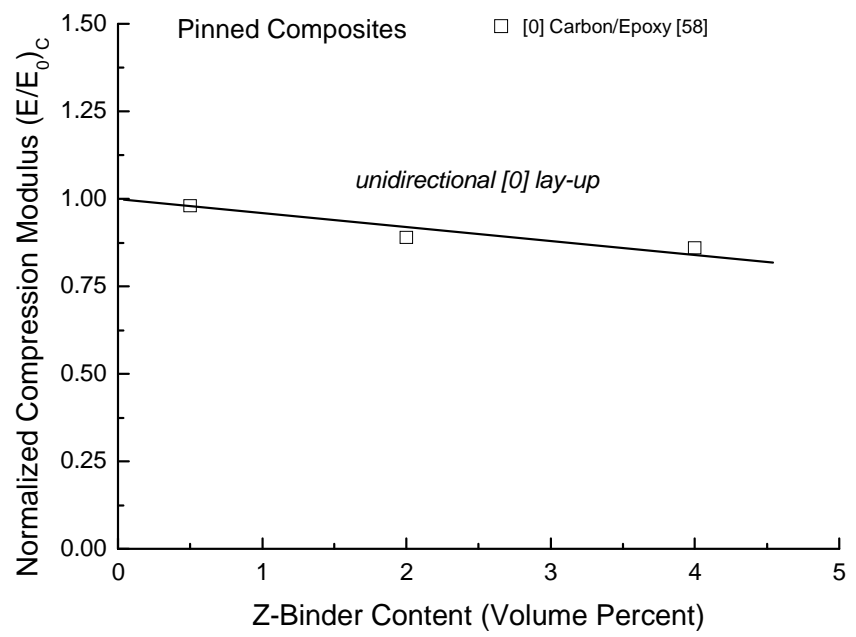

(b) 


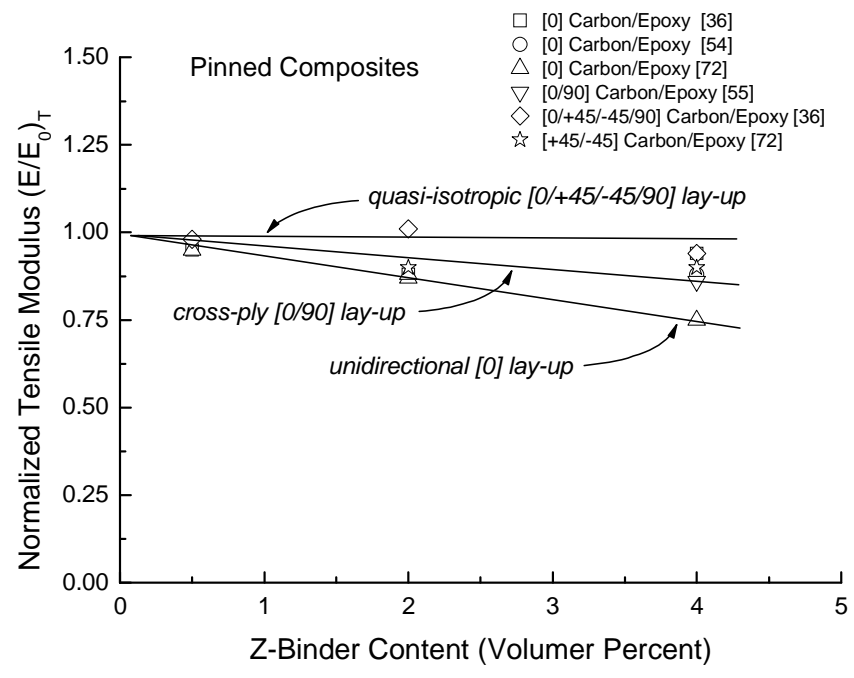

(c) 
Figure 11. Effect of z-binder content on the normalised flexural modulus of (a) stitched and (b) pinned composites. There is insufficient data to generate a plot for 3D woven composites.

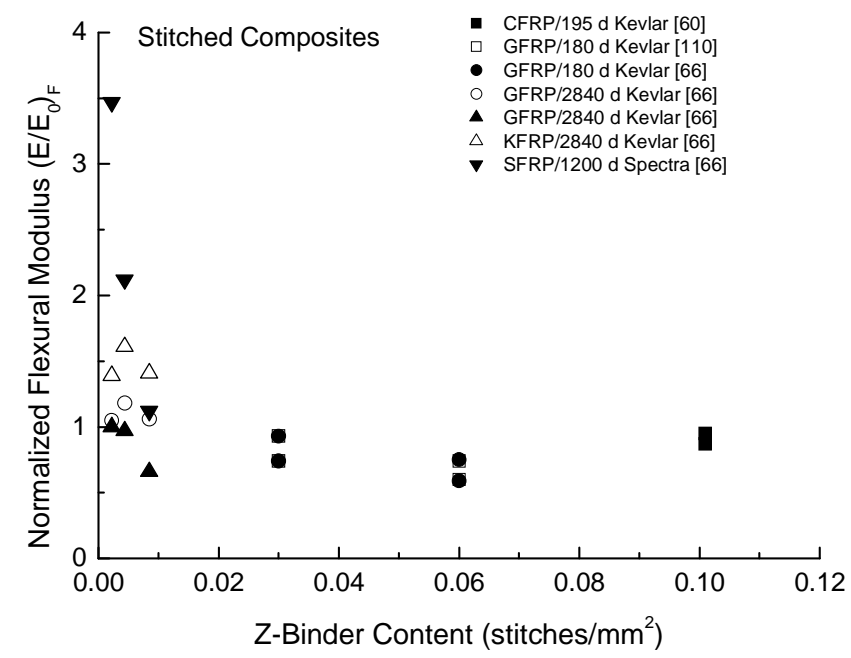

(a)

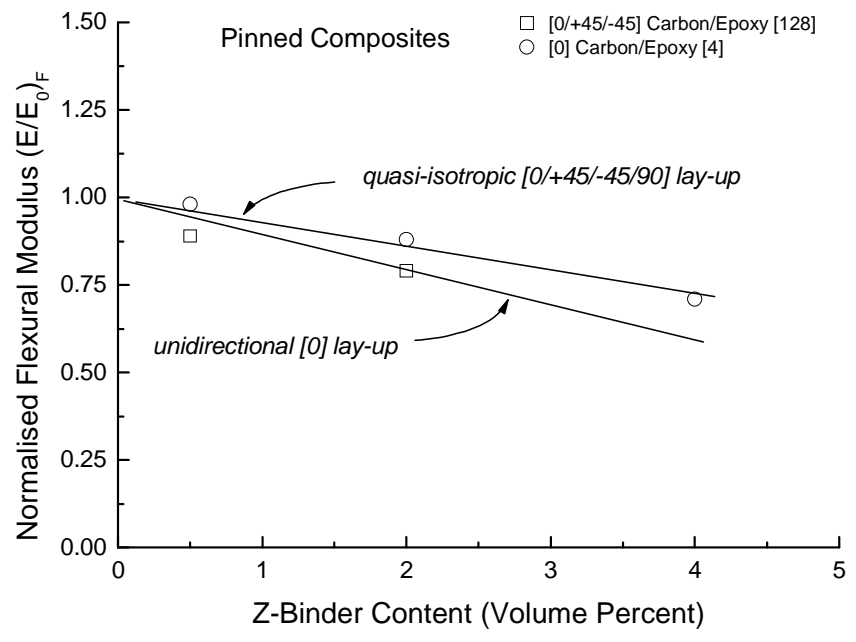

(b) 
Figure 12. Effect of stitch diameter (denier) on the normalized modulus properties at a fixed stitch content $\left(0.01\right.$ stitches $\left./ \mathrm{mm}^{2}\right)$.

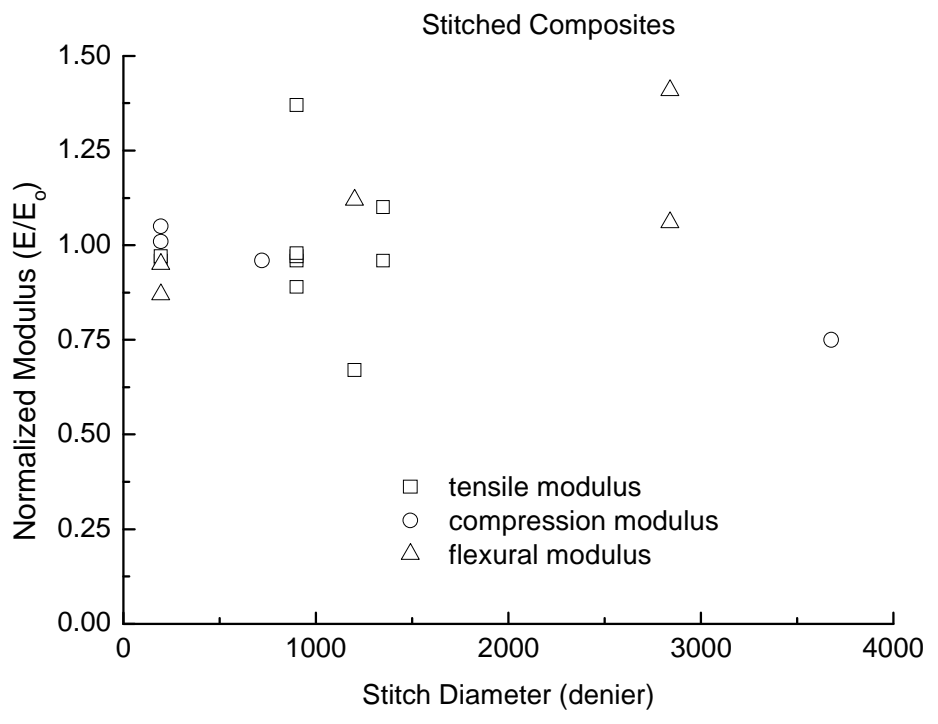


Figure 13. Effect of z-binder content on the normalised tensile strength of (a) 3D woven (b) stitched and (c) pinned composites.

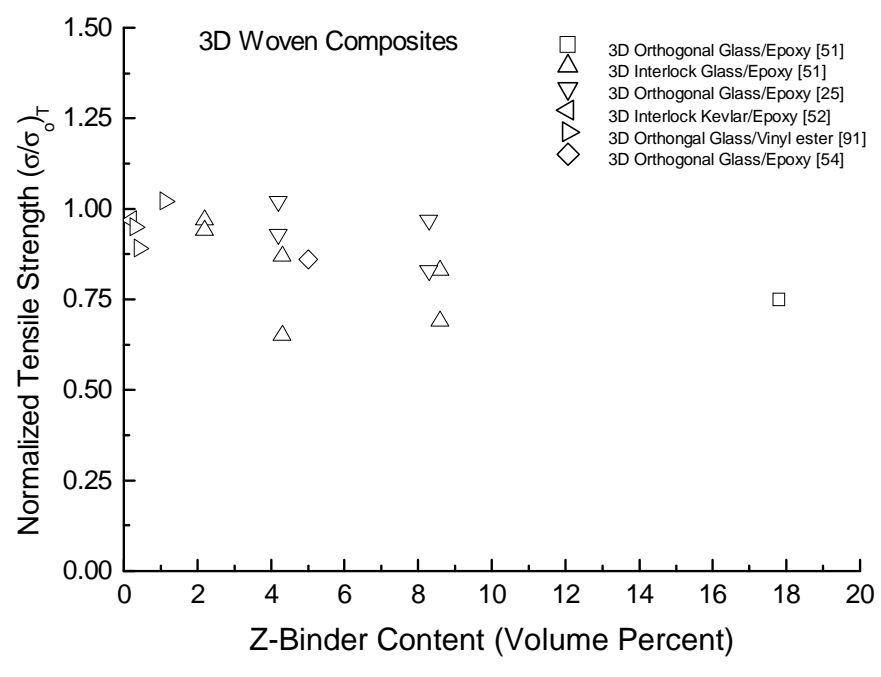

(a)

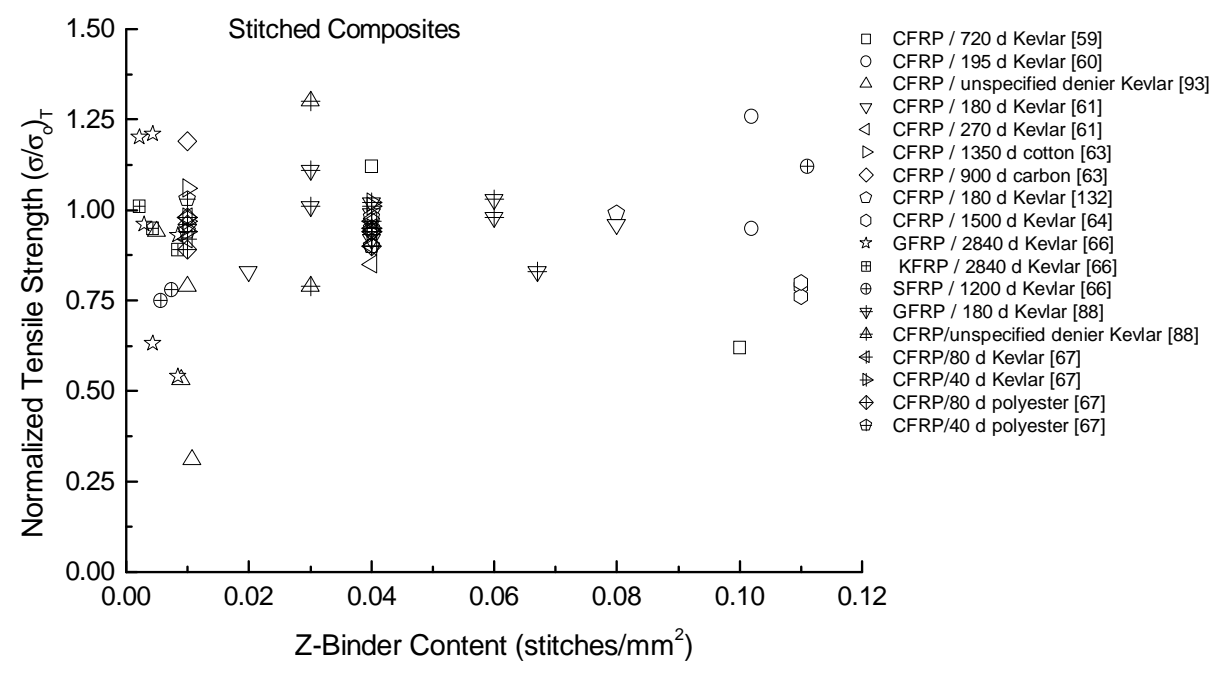

(b) 


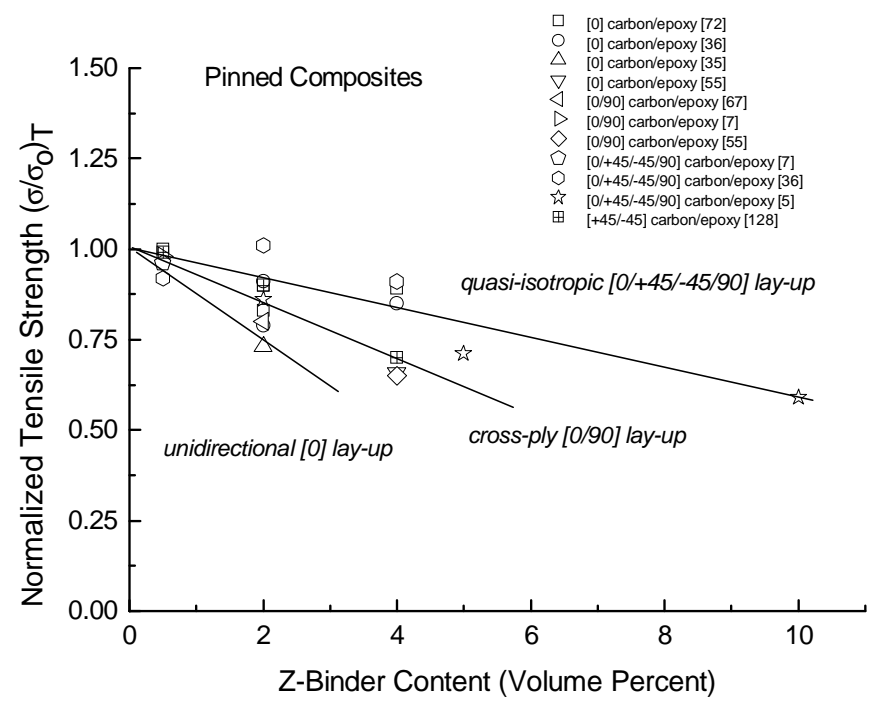

(c) 
Figure 14. Effect of z-binder content on the normalised compressive strength of (a) $3 \mathrm{D}$ woven (b) stitched and (c) pinned composites.

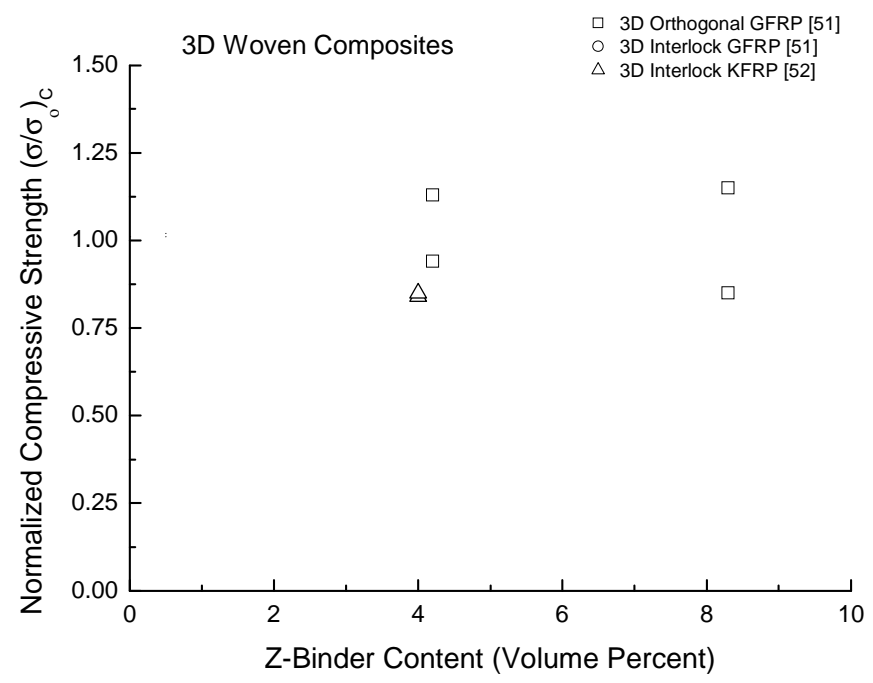

(a)

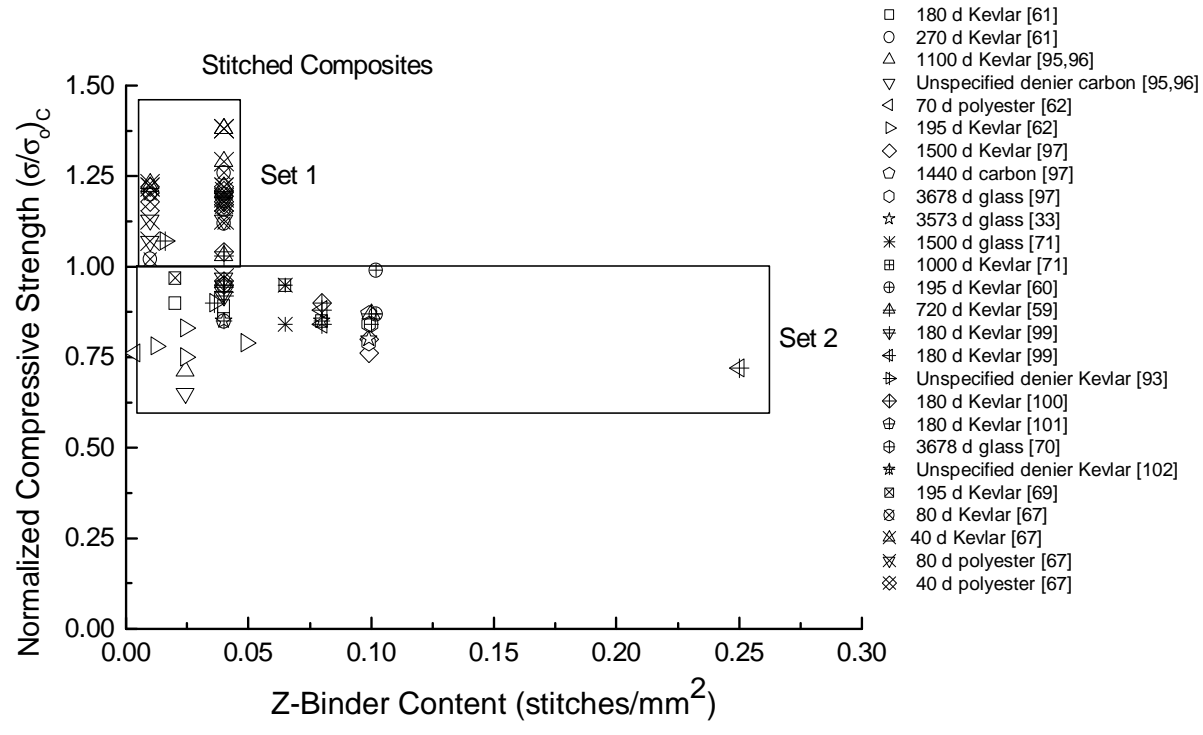

(b) 


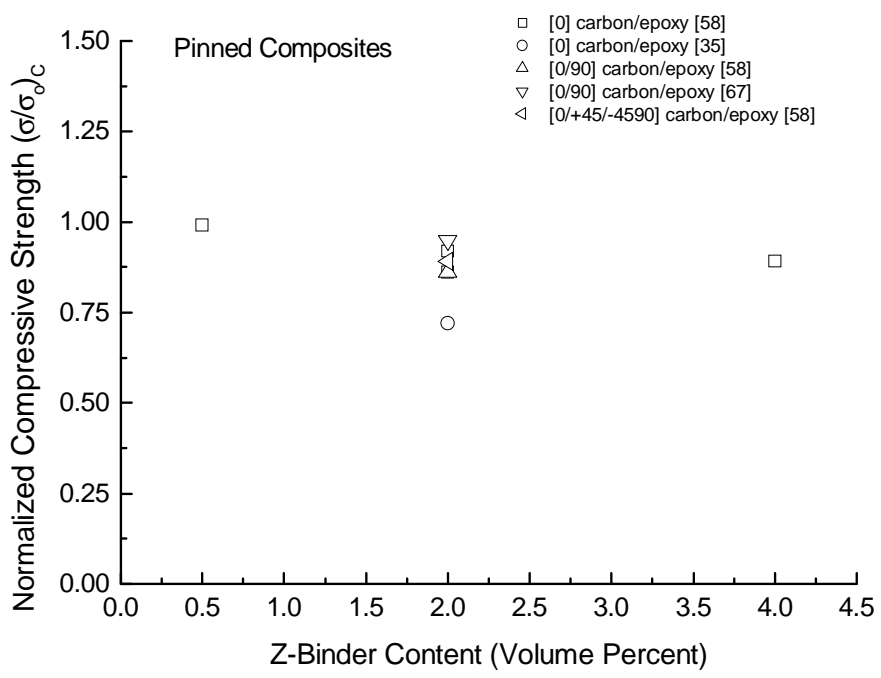

(c) 
Figure 15. Effect of z-binder content on the normalised flexural strength of (a) stitched and (b) pinned composites.

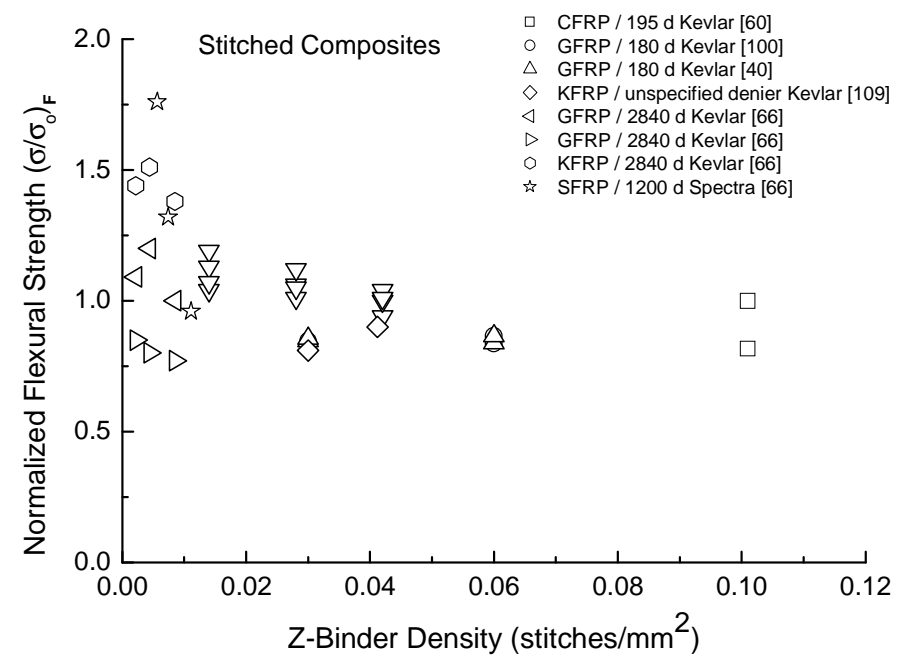

(a)

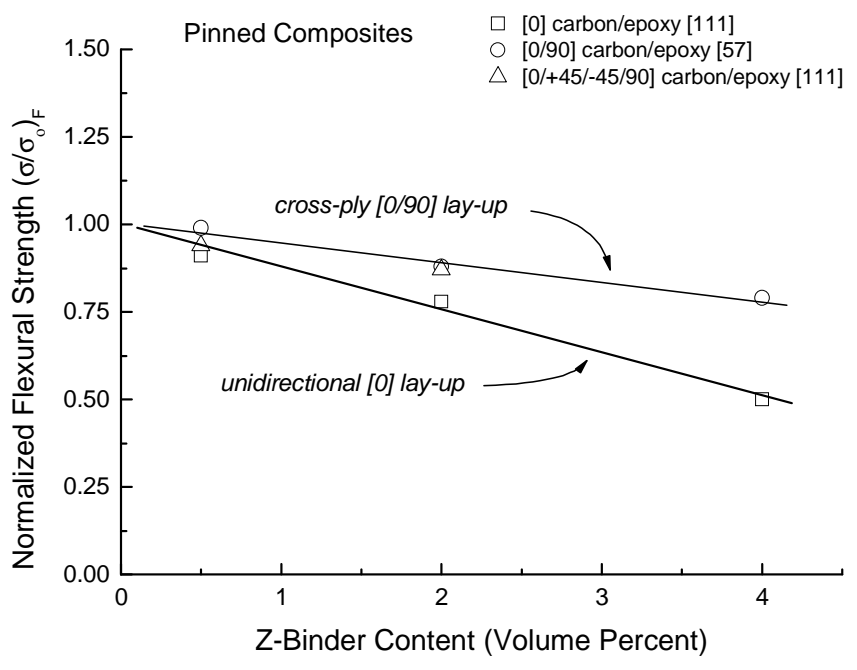

(b) 
Figure 16. Effect of z-binder content on the normalised interlaminar shear strength of (a) 3D woven, (b) stitched and (b) pinned composites.

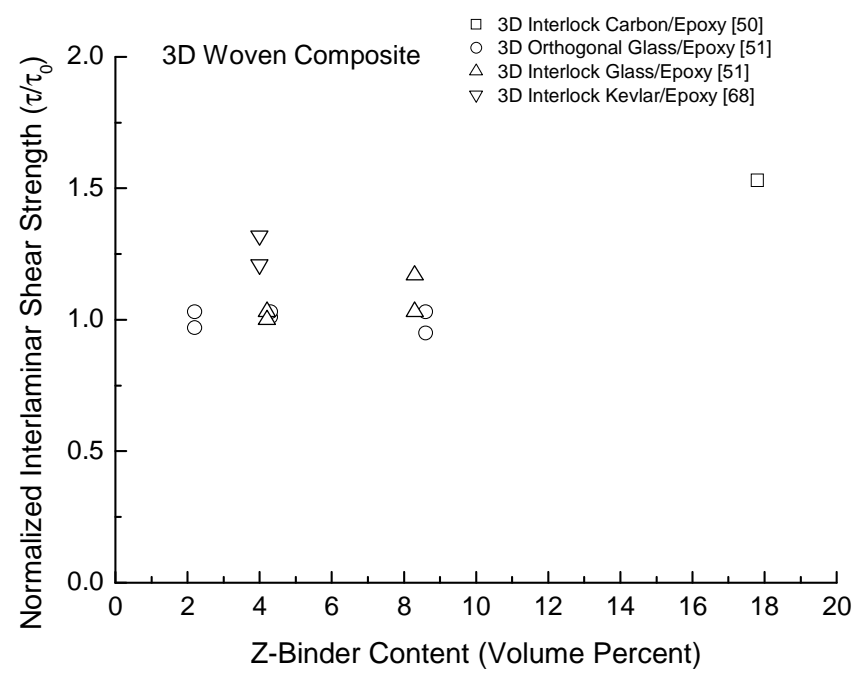

(a)

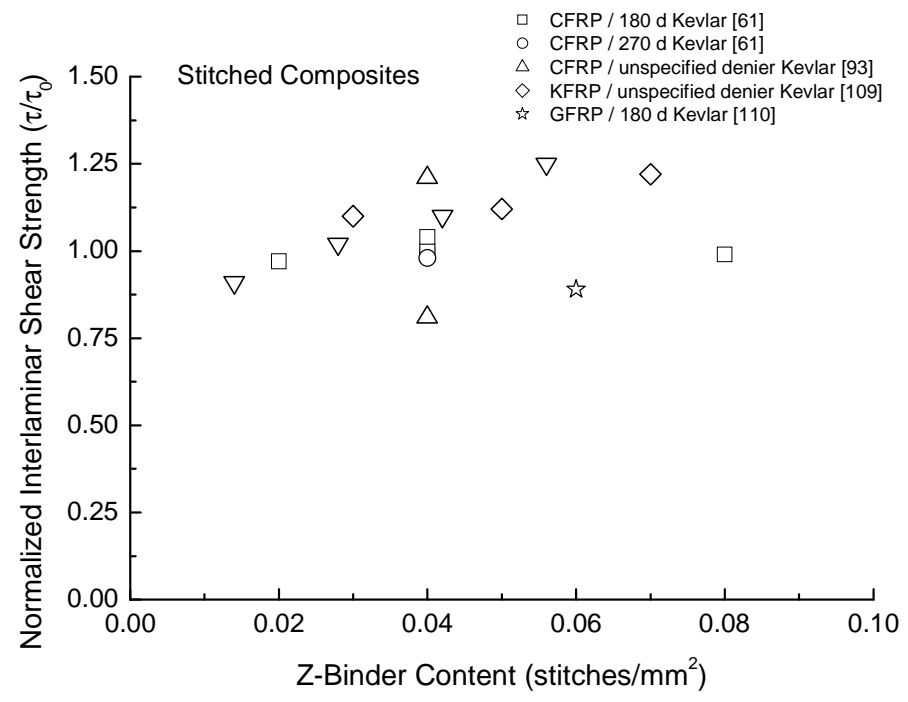

(b) 


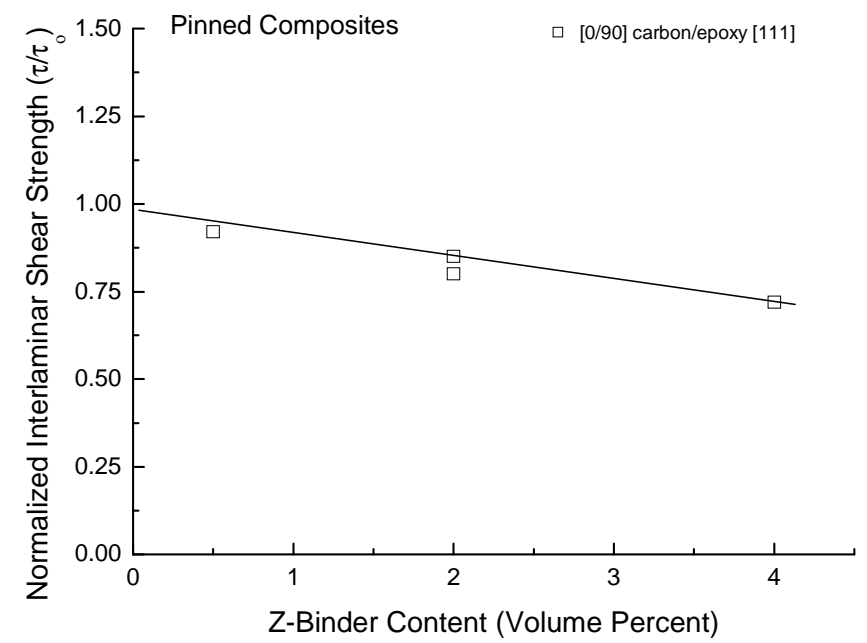

(c) 
Figure 17. Measured traction vs. displacement relations for (a) a single stitch [116,117] and (b) a single fibrous pin [11616] in a pre-cracked laminate under applied shear displacement. The stress is defined as the shear load divided by the normal cross-sectional area of the $z$-binder. The displacement is the total sliding displacement across a mid-laminar pre-crack. In these tests, both the stitches and pins were approximately normally oriented (pin angle $\phi$ as shown).

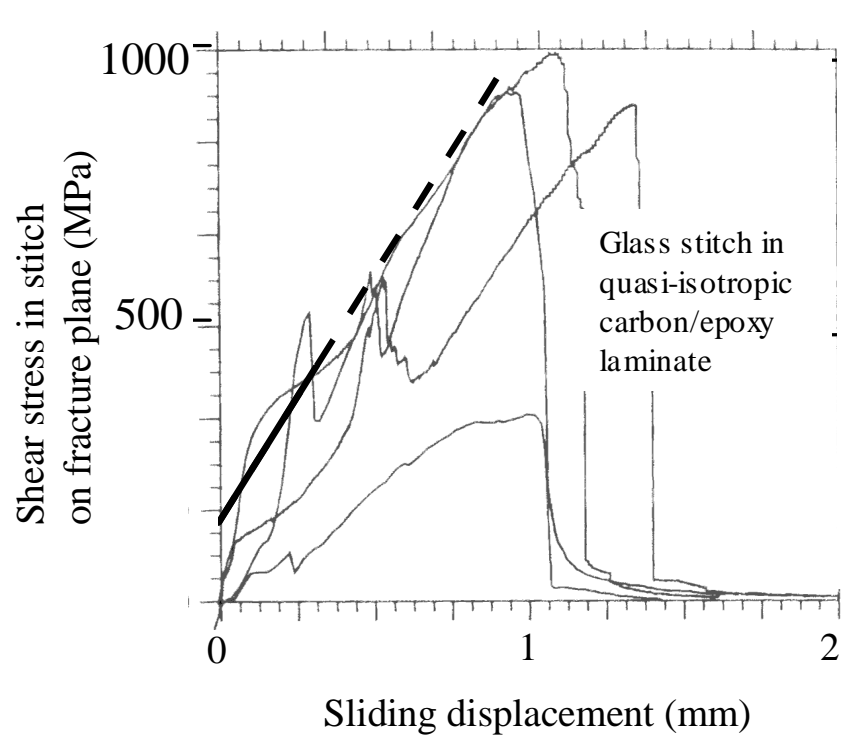

(a)

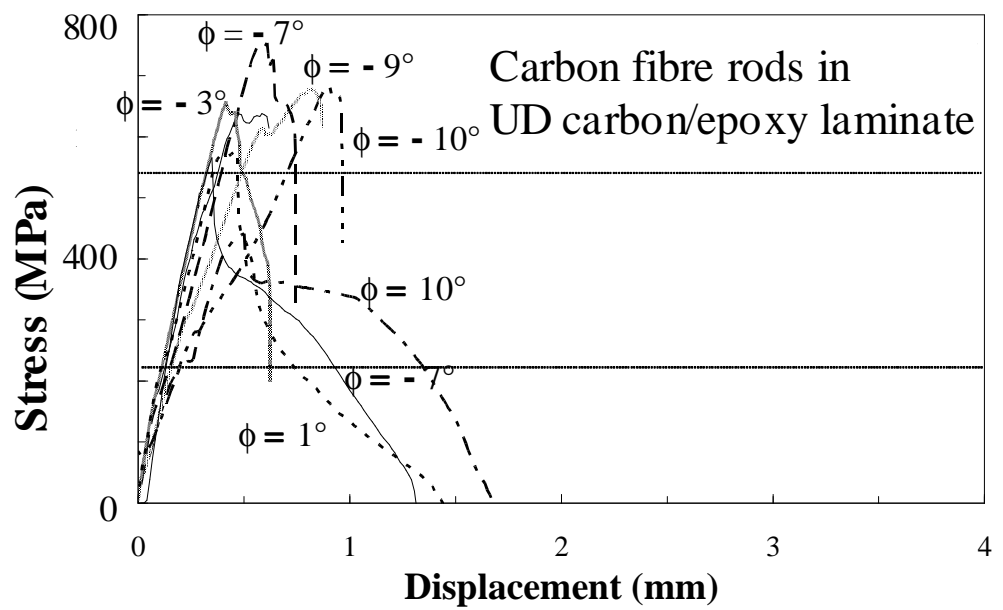

(b) 
Figure 18. S-N curves for (a) stitched and (b) pinned carbon-epoxy composite and their equivalent 2D laminate which show parallel curves. The stitched materials were fatigued under cyclic tension [90] and the pinned materials under cyclic bending [57]. Normalized S-N curves for the (c) stitched and (d) pinned materials in (a) and (b), respectively. The fatigue strength $\left(\sigma_{\mathrm{f}}\right)$ of the stitched and pinned materials is normalized against their monotonic strength $\left(\sigma_{\mathrm{o}}\right)$ of their $2 \mathrm{D}$ laminate.

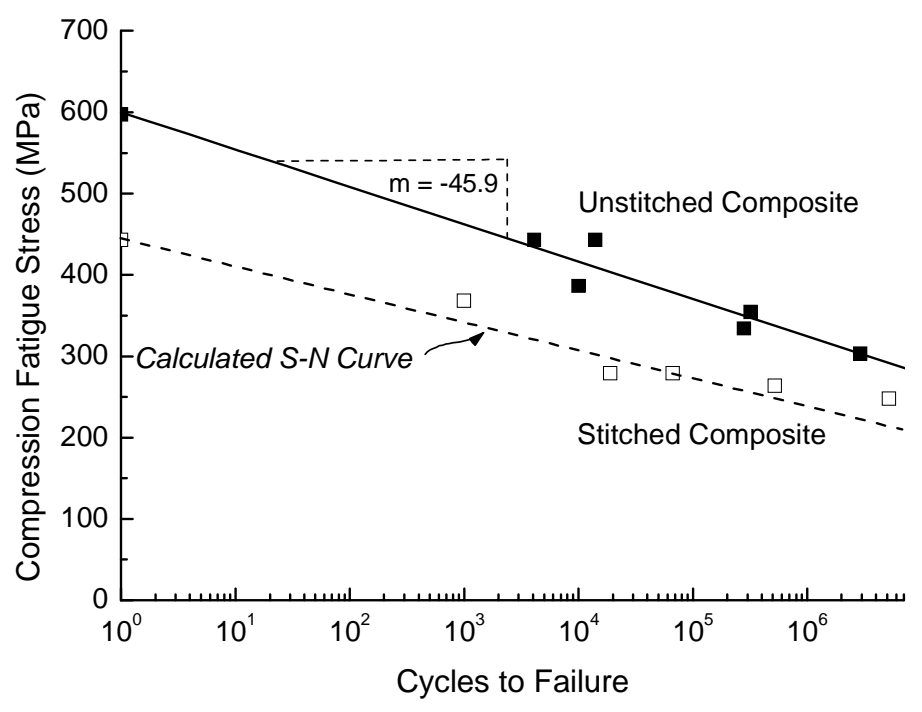

(a)

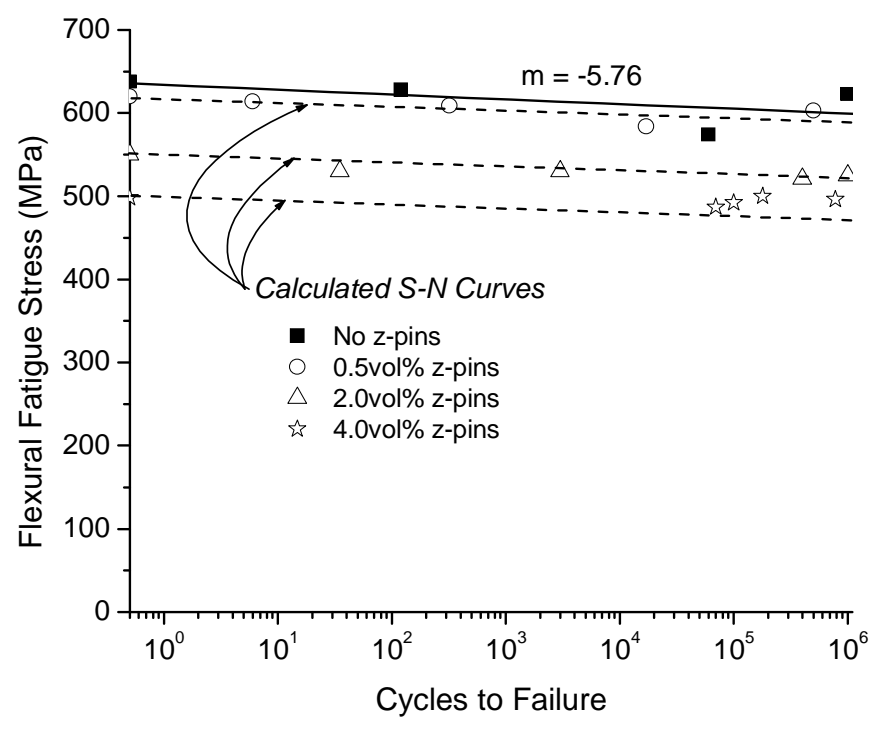

(b) 


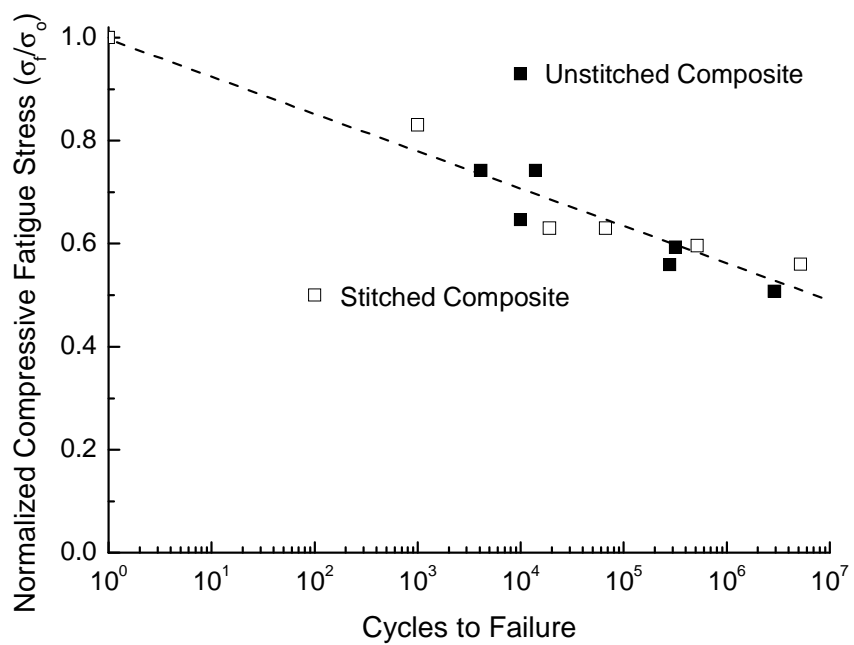

(c)

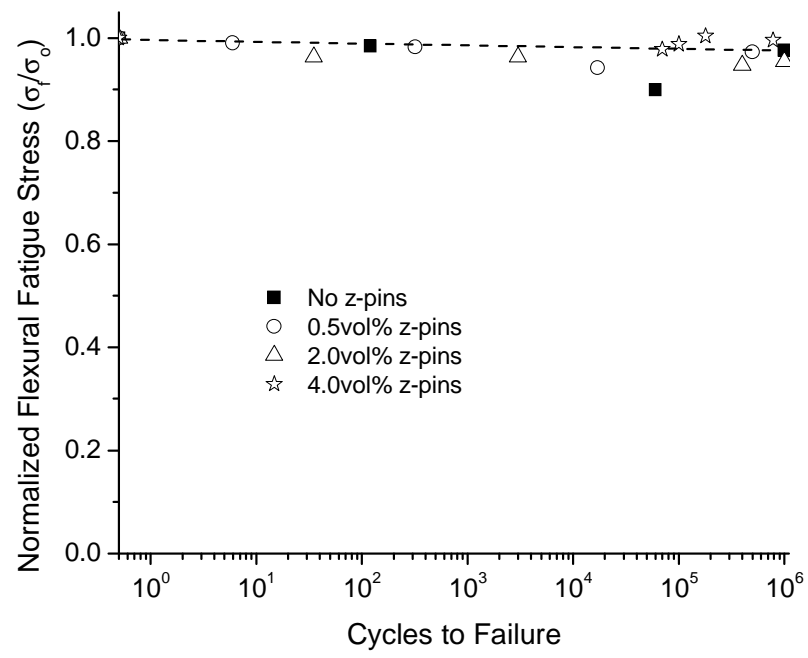

(d) 
Figure 19. S-N curves for (a) stitched and (b) pinned carbon-epoxy composites and their equivalent 2D laminates which do not show parallel trends. The stitched [90] and pinned [36] materials were fatigued under cyclic tension. Normalized S-N curves for the (c) stitched and (d) pinned materials in (a) and (b), respectively. The fatigue strength $\left(\sigma_{\mathrm{f}}\right)$ of the stitched and pinned materials is normalized against the monotonic strength $\left(\sigma_{\mathrm{o}}\right)$ of their equivalent 2D laminate.

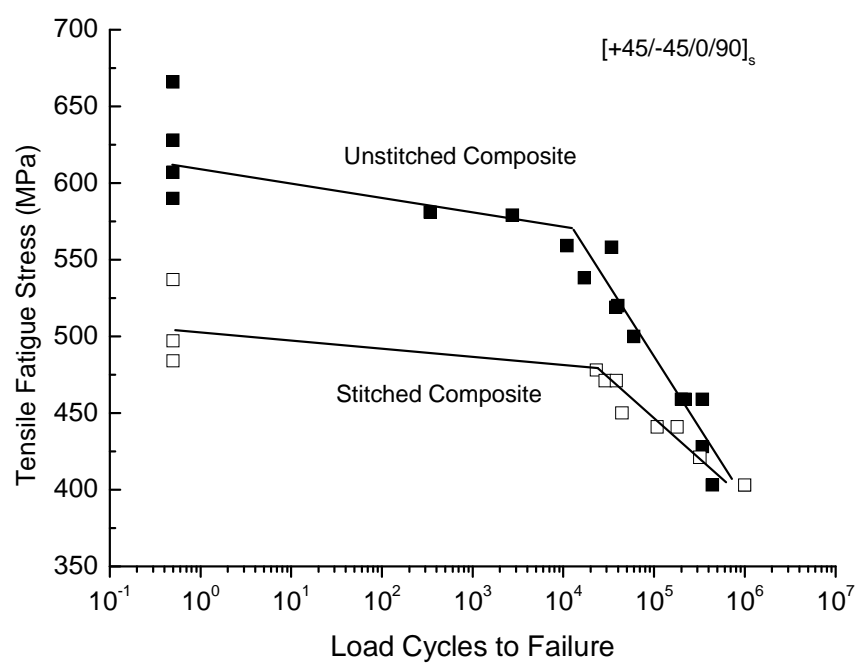

(a)

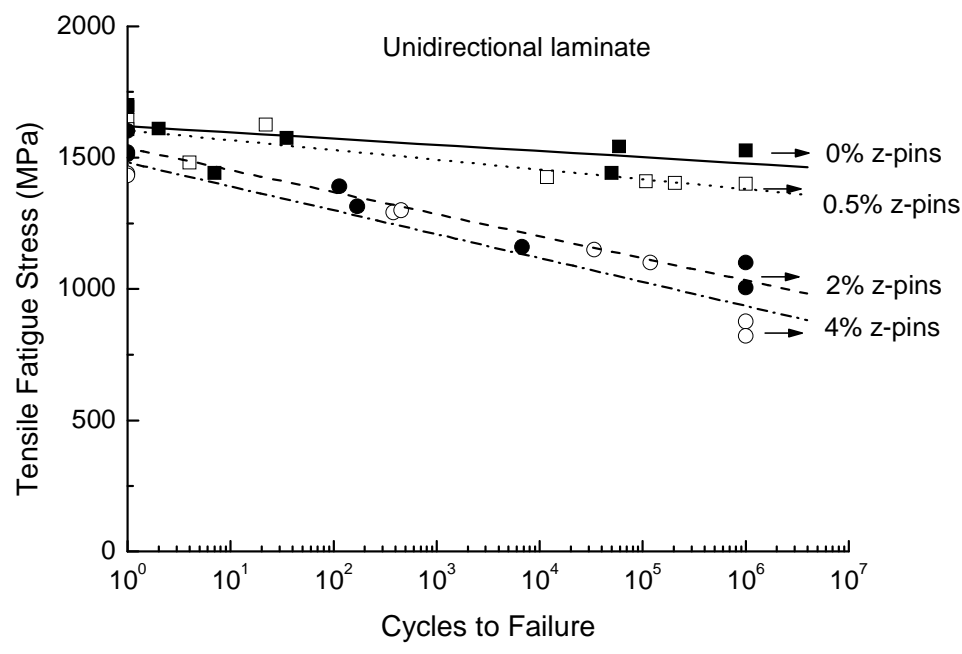

(b) 


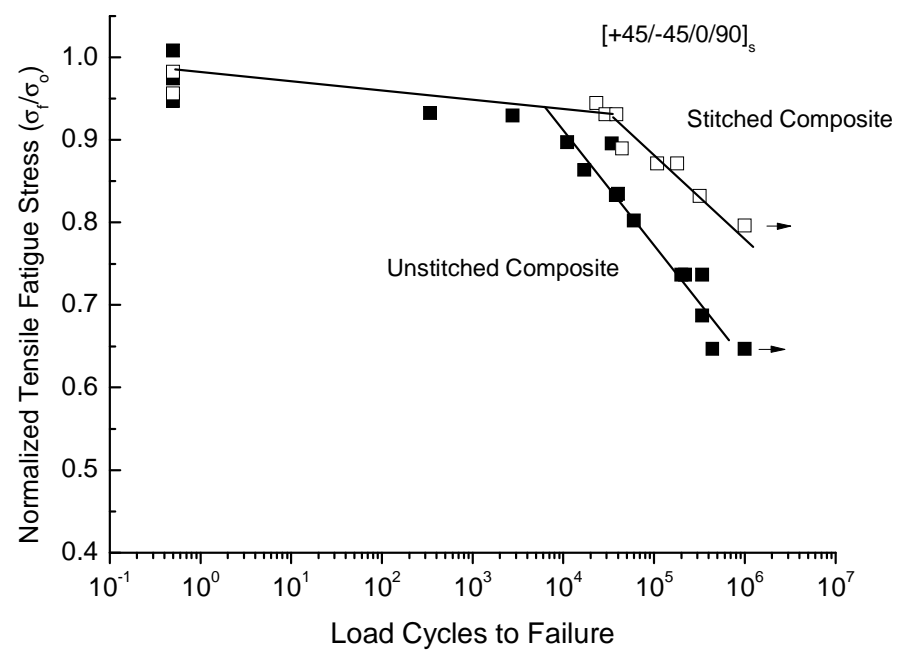

(c)

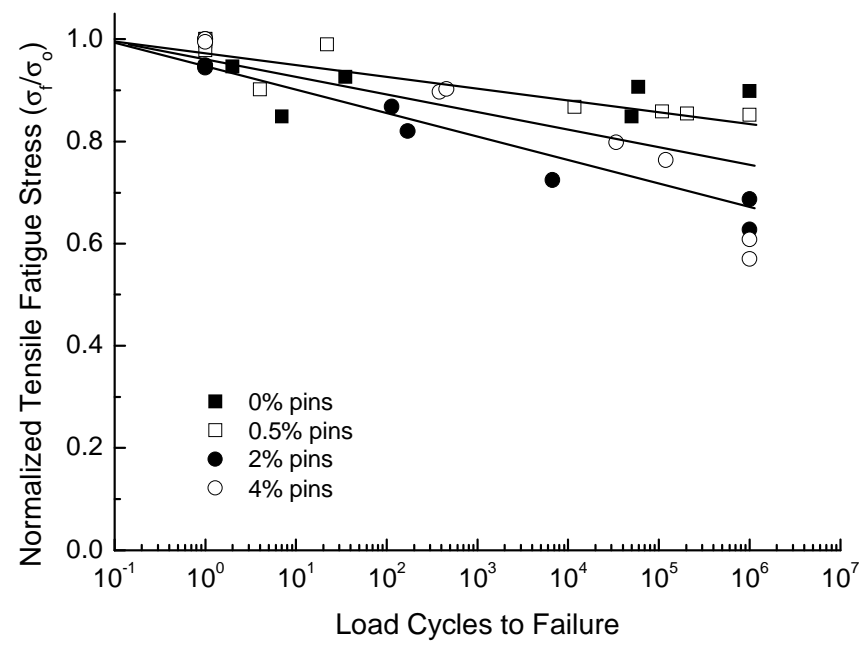

(d) 
Figure 20. Effect of $z$-binder content on the tensile fatigue life of 3D woven composites [91]. The fatigue stress $\left(\sigma_{\mathrm{f}}\right)$ is normalized against the monotonic strength $\left(\sigma_{\mathrm{o}}\right)$ for each material. The normalized tensile modulus $\left(\mathrm{E} / \mathrm{E}_{\mathrm{o}}\right)_{\mathrm{T}}$ and tensile strength $\left(\sigma / \sigma_{\mathrm{o}}\right)_{\mathrm{T}}$ are also given in the table inset.

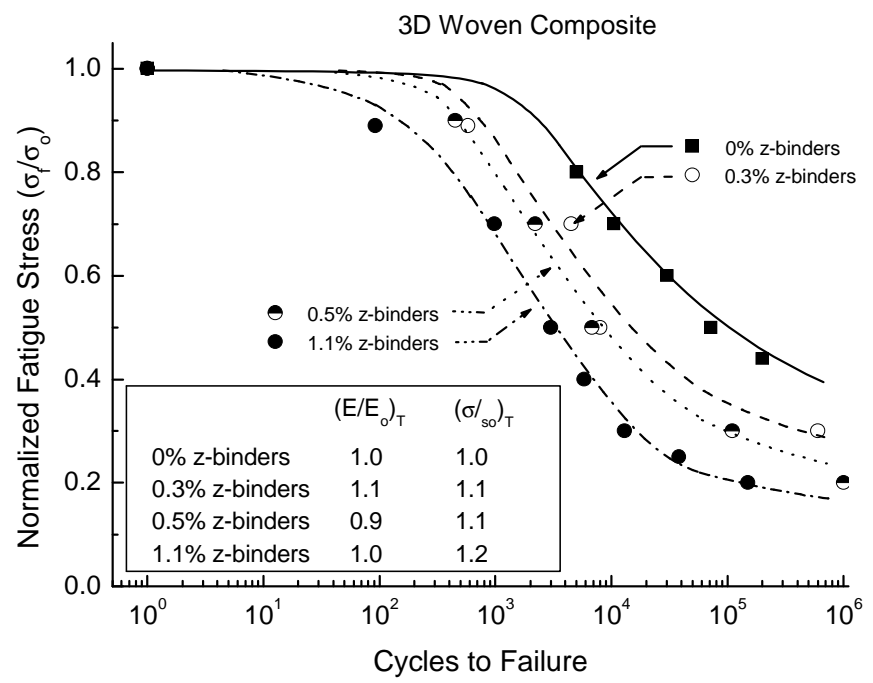

